\title{
Synergistic power of genomic selection, assisted reproductive technologies, and gene editing to drive genetic improvement of cattle
}

\author{
Maci L. Mueller(i) and Alison L. Van Eenennaam* (B)
}

\begin{abstract}
Genetic improvement of cattle around the globe has been, and will continue to be, an important driver of animal agriculture sustainability. There are several reproductive and molecular biotechnologies that are used in genetic improvement of cattle, and their impact on the rate of genetic progress is maximized when combined synergistically in a structured breeding program with a clear breeding objective. One of the most recently developed and increasingly popular tools, gene editing, allows animal breeders to precisely add, delete, or replace letters in the genetic code so as to influence a specific trait of interest (e.g., disease resistance), in as little as one generation. However, for gene editing to be an important factor for genetic improvement, it must integrate smoothly into conventional cattle breeding programs to maintain or accelerate rates of genetic gain. This review first summarizes the current state of key reproductive and molecular biotechnologies available for the genetic improvement of cattle, and then discusses potential strategies for effectively incorporating gene editing into cattle genetic improvement programs and methods for disseminating traits improved via gene editing. Moreover, it examines how genetic improvement strategies, including the use of gene editing, will differ depending on the cattle industry sector (i.e., dairy or beef), and the region of the world in which they are being deployed.
\end{abstract}

Keywords: Biotechnology, Breeding, Cattle, Gene editing, Genomic selection, Assisted reproductive technologies, Sustainability, Livestock, Dairy, Beef

\section{Introduction}

Genetic improvement is a powerful tool for improving animal agriculture sustainability because the results are permanent and cumulative. Unlike nutritional and animal health interventions, which require continuous inputs, genetic improvements made in one generation are passed onto the next. Moreover, genetic solutions for animal health and welfare issues often require less labor and material inputs than chemical or mechanical methods. For example, polled, or hornless, genetics can eliminate the need for physical dehorning of animals, which is undertaken to ensure both worker and animal safety, can

*Correspondence: alvaneenennaam@ucdavis.edu

Department of Animal Science, University of California, Davis, CA, USA save livestock producers both time and money, in addition to addressing an animal welfare concern (Gottardo et al. 2011; Thompson et al. 2017).

Sustainable agriculture and increased production efficiency go hand-in-hand. Efficiency is defined as achieving maximum productivity with minimum waste, or in other words, producing more product with the same or even fewer resources. Livestock genetic improvement programs, beginning with selective breeding using statistical prediction methods, such as estimated breeding values (EBVs), and more recently genomic selection (GS), in combination with assisted reproductive technologies (ART) have enabled more accurate selection and intense utilization of genetically superior parents for the next generation to accelerate rates of genetic gain. Genetic

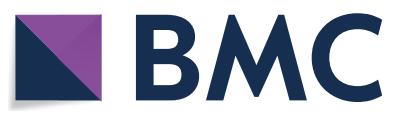

(c) The Author(s) 2022. Open Access This article is licensed under a Creative Commons Attribution 4.0 International License, which permits use, sharing, adaptation, distribution and reproduction in any medium or format, as long as you give appropriate credit to the original author(s) and the source, provide a link to the Creative Commons licence, and indicate if changes were made. The images or other third party material in this article are included in the article's Creative Commons licence, unless indicated otherwise in a credit line to the material. If material is not included in the article's Creative Commons licence and your intended use is not permitted by statutory regulation or exceeds the permitted use, you will need to obtain permission directly from the copyright holder. To view a copy of this licence, visit http://creativecommons.org/licenses/by/4.0/. The Creative Commons Public Domain Dedication waiver (http://creativeco mmons.org/publicdomain/zero/1.0/) applies to the data made available in this article, unless otherwise stated in a credit line to the data. 
gain is the amount of increased performance, or the improvement in average genetic value, in a population that is achieved annually through selection. Increased animal performance based on genetic improvement results in more product produced per animal, so fewer animals are required to meet the same amount of demand, which reduces the environmental impact per unit of livestock product. Therefore, increasing rates of genetic gain can improve livestock production efficiency and ultimately the sustainability of animal agriculture.

The power and scale of genetic improvement is wellillustrated by the increased efficiency of the United States (U.S.) dairy cattle population from 1944 to today, which now produces over $80 \%$ more milk with $65 \%$ fewer cows. This was enabled by a more than four-fold increase in milk production per cow, from $2000 \mathrm{~kg} / \mathrm{cow}$ in 1944 to 10,000 kg/cow in 2017 (Capper and Cady 2019; Capper et al. 2009). It is estimated that approximately $50 \%$ of the increased productivity per animal observed can be attributed solely to the increased rate of genetic gain obtained by the widespread use of artificial insemination (AI) over natural service breeding alone (Bertolini and Bertolini, 2009). Overall, the dramatic decrease in the number of dairy cows (25.6 million to 9 million) required to meet the demand, due to increased productivity per animal largely from improved genetics, reduced the current environmental impact of a glass of milk to approximately one third of that associated with the same glass of milk in 1944 (Capper and Cady 2019; Capper et al. 2009).

In livestock breeding programs, the breeder's equation is used to measure the rate of genetic gain $(\Delta G)$ towards the breeding objective of a given production system. It consists of four components: $\Delta G=\frac{i \times r \times \sigma_{\mathrm{A}}}{L}$, where $i$ is selection intensity (how extensively the most elite animals are used as parents of the next generation); $r$ is selection accuracy (how well the EBV represents the true breeding value of selection candidates); $\sigma_{\mathrm{A}}$ is genetic diversity (as measured by the additive genetic standard deviation of the population); and $L$ is the generation interval (interval length calculated as the average age of parents when progeny are born) (Lush 1937).

Strategies to improve rates of genetic gain in a population involve increasing the components of the breeder's equation in the numerator and decreasing the denominator, or generation interval. It is important to note that the foundation of genetic improvement is a well-structured breeding program with a clear breeding objective, and routine recording of pedigree and performance information on the population under selection. Genomic information can additionally improve the accuracy of the relationship matrix compared to pedigree information alone. Within a structured breeding program, reproductive and molecular biotechnologies, such as ART and
GS, can be applied to further accelerate rates of genetic gain by influencing one or more of the components of the breeder's equation.

To increase selection intensity, ART [e.g., AI and embryo transfer (ET)] have been incorporated into cattle breeding schemes. Concurrently, the development of high-throughput genotyping of single nucleotide polymorphisms (SNPs), has enabled GS to predict the genetic merit of an animal based on its DNA (Meuwissen et al. 2001). Using GS has both improved the accuracy of selection and reduced the generation interval. Additionally, GS can provide information on traits that are recorded late in life, or that are difficult or expensive to record (García-Ruiz et al. 2016; Hayes et al. 2013; Meuwissen et al. 2013). Moreover, the benefits of each of these tools, GS and ART, can be maximized when used synergistically to accurately select young animals, which can markedly reduce the generation interval and ultimately accelerate genetic gain (Fig. 1) (Kadarmideen et al. 2015; Loi et al. 2016).

Genome or gene editing ( $\mathrm{GnEd}$ ) is one of the most recently developed tools for genetic improvement. This advanced biotechnology allows animal breeders to very precisely target the addition, deletion, or replacement of base pairs in the genetic code to influence traits of interest. Specifically, GnEd refers to the use of site-directed nucleases (i.e., nucleic acid cleaving enzymes) to precisely introduce double stranded breaks (DSB) in the DNA at a targeted location in the genome (Gaj et al. 2013). When the cell attempts to repair the DSB, it can result in the disruption (knockout) of a gene, or if a donor repair nucleic acid template is provided, the insertion (knock-in) of an allele or gene from the same species (intraspecies or cisgenic) or possibly a different species (interspecies or transgenic).

In cattle breeding programs, GnEd offers promising opportunities to introduce useful genetic variation from one breed of cattle to another in the absence of undesired linkage drag, or even beneficial traits from different species. Currently, GnEd research in cattle has focused on and is well-suited for improving monogenic, or Mendelian, traits. Mendelian traits are controlled by one to a few loci that each have large effects, and most are qualitative traits, such as horned/polled or coat color. Although, there are a few known single genes that have large effects on important quantitative traits. For example, a naturally occurring mutation in the myostatin $(M S T N)$ gene present in some cattle breeds like Belgian Blue, results in a substantial increase in the quantitative trait, muscle yield (Kambadur et al. 1997; McPherron and Lee 1997). If $\mathrm{GnEd}$ is used to target a gene that has a large effect on a quantitative trait, like MSTN, then GnEd has the potential to increase genetic variation of that trait in the 


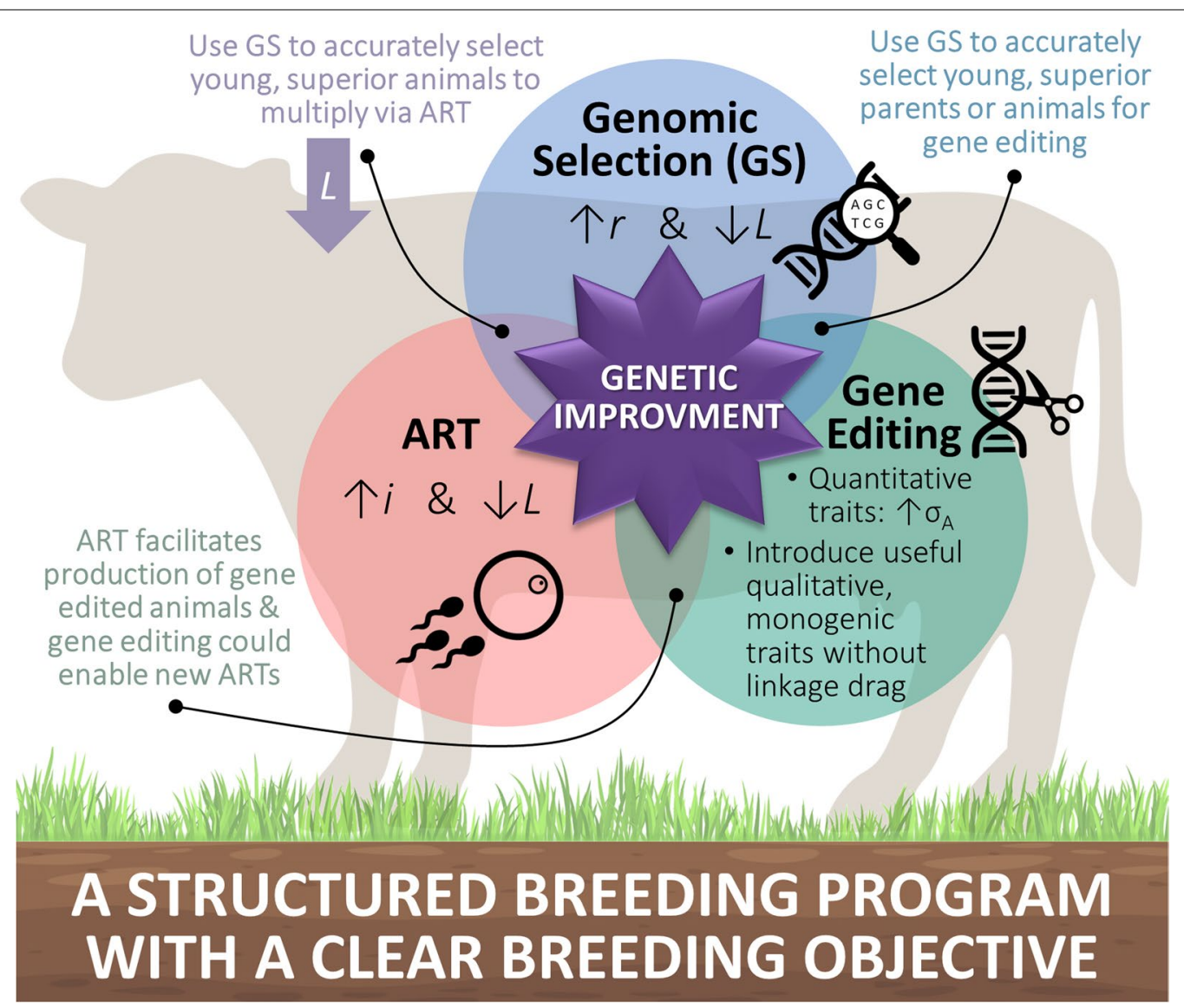

Fig. 1 Schematic illustrating the synergistic relationships between genomic selection (GS), assisted reproductive technologies (ART), and gene editing for the genetic improvement of cattle. The foundation of genetic improvement is a well-structured breeding program with a clear breeding objective. Within a structured breeding program, reproductive and molecular biotechnologies, such as ART and GS, can be applied to further improve rates of genetic gain by effecting one or more of the components of the breeder's equation (Lush 1937): (1) increase selection intensity ( $i$ ), (2) increase selection accuracy $(r),(3)$ decrease the generation interval $(L)$, and $(4)$ increase genetic variation $\left(\sigma_{A}\right)$

population, thus accelerating the rate of genetic gain. It should be noted that complete MSTN knockouts have also resulted in increased birth weights, which can cause dystocia issues (i.e., calving difficulties), so more precise MSTN mutations will likely be required for practical applications of this target (Proudfoot et al. 2015).

However, most of the traits that animal breeders want to improve are polygenic and quantitative (e.g., marbling, growth, feed efficiency, etc.). For these traits, quantitative genetics and GS have been, and will continue to be, the major driver for genetic improvement. Additionally, GnEd in livestock is only possible through the use of ART. Therefore, the potential of GnEd can only be fully realized when used in conjunction with ART and GS in a structured breeding program with a clear breeding objective to accelerate genetic gain by concurrently altering multiple components of the breeder's equation (Fig. 1) (Bishop and Van Eenennaam 2020; Jenko et al. 2015; McLean et al. 2020; Van Eenennaam 2017).
Given that there are a wide variety of tools for genetic improvement in cattle, this review first summarizes the current state of key reproductive and molecular biotechnologies, and then discusses their synergistic potential when employed jointly. There is a primary focus on how the increasingly popular modern biotechnology, GnEd, is being used for genetic improvement of cattle and strategies for effectively incorporating it into existing cattle breeding programs. Moreover, we discuss how genetic improvement strategies, including the use of GnEd, will differ depending on the cattle industry sector (i.e., dairy or beef) being targeted, and the region of the world in which they are being deployed.

\section{Considerations for genetic improvement of cattle in beef versus dairy systems}

Advanced reproductive and molecular biotechnologies are often easier to cost effectively implement in the breeding pyramid of vertically integrated, "high-input" 
(intensive), industries. In such systems, external inputs such as supplementary feeds, veterinary medicines and ART are relatively easy to obtain and widely used. Additionally, in vertically integrated programs the return on investment in performance recording of each nucleus animal can be recouped through thousands, or even millions, of genetic descendants (Van Eenennaam et al. 2014).

Compared to other livestock species, cattle have a long generation interval and low fecundity, which slows genetic progress. Nevertheless, the dairy industry was well-positioned for rapid adoption of GS due to its industry-wide selection goal (e.g., Lifetime Net Merit, $\mathrm{NM} \$$ in the U.S.), widespread use of AI, large number of high accuracy AI sires, primary use of purebred animals (e.g., Holstein), extensive and uniform phenotype data collection, and central evaluation program to receive genotypes. Moreover, large breeding organizations were willing to fund genotyping because they received a clear cost savings in terms of identifying AI sires at a young age ( $<1$ year-old) compared to previous progeny testing schemes ( $>5$ years-old) (Wiggans et al. 2017).

In contrast, genetic progress in beef cattle selection programs has been slower and industry-wide rates of genetic gain lag well below what is possible (Banks 2005). This is due to a multitude of factors including the difficulty of developing an industry-wide breeding objective in large part because of industry segmentation. The beef industry has a large number of ranches/decision makers raising animals in very diverse environments and selection decisions are made at the seedstock level without good linkages to performance metrics in the commercial cow-calf, feedlot, or processing sector. Also, the beef industry is comprised of multiple breeds and breed associations all collecting separate data, has limited to no data recording on several economically relevant traits (e.g., female reproduction and feed efficiency), has lower producer adoption of economic indexes, and a limited use of AI (Van Eenennaam et al. 2014). Moreover, a large proportion of the world's beef cattle are located in tropical and subtropical environments, which requires additional traits, such as tolerance or resistance to environmental stressors, to be included in the breeding objective and those traits are typically very difficult or expensive to effectively record for genetic improvement purposes and they may have antagonistic relationships with productive attributes.

\section{Genomic selection (GS) opportunities}

The development of high-throughput genotyping of SNPs enabled the development of approaches to predict an animal's genetic merit based on its DNA (Meuwissen et al.
2001). In GS, SNP effects are estimated using genotyped individuals that are phenotyped for the characteristics of interest (i.e., training population), and then genomic estimated breeding values (GEBVs) can be predicted for any genotyped individual by using only its SNP genotypes and estimated SNP effects. GS has been used in cattle to improve accuracy of selection, reduce the generation interval, and to provide useful information on traits that would otherwise be difficult to measure (García-Ruiz et al. 2016; Meuwissen et al. 2013). Genetic improvement in cattle, using GS for hard to measure traits like feed efficiency, cow longevity and fertility, has the potential to reduce the environmental footprint per unit of production (Barwick et al. 2019; Fennessy et al. 2019; Hayes et al. 2013; Pryce and Haile-Mariam 2020; Quinton et al. 2018).

Furthermore, improving efficiency of cattle production through exploitation of genomics can be considered a public good (Berry et al. 2016). For example, in Ireland this concept has been recognized by public support of genotyping cattle to facilitate GS. In 2016, a multibreed genomic evaluation in beef cattle was launched and a monetary incentive was provided for beef producers to genotype females, more extensively phenotype females, and to retain genomically tested high-index females as herd replacements to increase the efficiency of the national herd. To date, the Irish Cattle Breeding Federation (ICBF) has genotyped almost 2 million animals. This program provided the data required to validate that higher maternal index females, on average, calved for the first time at a younger age, had shorter calving intervals, survived longer, and were also expected have a lower mature weight. An accelerated rate of genetic gain in the Irish maternal index was observed following the deployment of genotyping incentives and genomic predictions (Twomey et al. 2020). All of these improvements would be expected to reduce the environmental impact per unit of beef production in this system.

\section{Assisted reproductive technologies (ART) adoption}

ART is the term used to describe treatments and procedures which involve the manipulation of reproductive cycles, gametes, or embryos. In cattle breeding schemes, ART including AI, cryopreservation of sperm or embryos, estrus synchronization, multiple ovulation ET (MOET), ovum-pick up (OPU) and in vitro embryo production (IVP), sex determination of sperm or embryos, and nuclear transfer (NT) have been incorporated to increase selection intensity, which can accelerate rates of genetic gain. Globally, the most widely used ART in cattle is AI (Baruselli et al. 2018). AI allows females around the world to be inseminated by genetically superior bulls via cryopreserved semen, which increases the 
selection intensity of males and thus accelerates rates of genetic gain. India, which is the country with the second largest number of cattle in the world in 2019 (193 million head, not including over 110 million Buffalo, Mithun and Yak), behind Brazil (215 million head), currently has the world's largest AI infrastructure. This consists of 49 semen stations producing 66.8 million doses of frozen semen annually. Additionally, there has been an increase in the uptake of sexed semen in India to reduce the number of male calves born into dairy herds (Ojango et al. 2016).

In some countries, the adoption of AI has been markedly skewed towards the dairy sector. For instance, while AI has been widely adopted by the U.S. dairy industry (>80\%) (Capper and Cady 2019; VanRaden 2007), to date it has seen limited uptake in the U.S. beef industry (USDA 2020). Only $12 \%$ of U.S. beef producers report using AI, and even fewer (7\%) use estrus synchronization. In 2017, this resulted in less than $10 \%$ of all females being bred via AI. A larger portion of beef heifers (19\%) were bred via AI compared to only 7\% of cows (USDA 2020). Additionally, in Northern Australia, which accounts for over $50 \%$ of Australia's total beef cattle population, it is estimated that $\mathrm{AI}$ is used by less than $1 \%$ of breeding herds (MLA 2015). This low adoption rate in the beef industry is largely due to the difficulty in extensive systems of identifying females in estrus and constraining them to allow AI (USDA 2020).

To eliminate the burden and challenge of estrus detection, timed AI (TAI) was developed (Pursley et al. 1995).
Additionally, TAI allows anestrous cows to be inseminated and has enabled conception to be more clustered to the beginning of the breeding season, thus increasing the reproductive and productive efficiency of farms (Baruselli et al. 2018). South America has widely adopted TAI. In 2017, more than 15 million breeding females were inseminated using TAI in Brazil, Argentina and Uruguay (Mapletoft et al. 2018). Specifically in Brazil, the widespread adoption of TAI resulted in a remarkable $220 \%$ increase in the Brazilian market for bovine semen units, from 7 million doses in 2002 to 15.5 million in 2018 (Fig. 2) (Baruselli et al. 2019). Over this time period (2002-2018), the percentage of female cattle in Brazil that were inseminated using $\mathrm{AI}$ more than doubled from $5.8 \%$ to $13.1 \%$, totaling approximately 9.5 million head (13.6\% of beef and $10.8 \%$ of dairy). Importantly, the large majority $(86.3 \%)$ of these inseminations were via TAI (Fig. 2). Overall, it has been estimated that TAI returns more than half a billion U.S. dollars per year to the Brazilian beef production chain due to genetic improvement in economically important traits, such as growth and carcass merit, as compared to natural service (Baruselli et al. 2018).

While AI and TAI enable increased selection intensity of males, MOET and OPU-IVP have allowed for increased selection intensity of females. In livestock, ET is the process of placing an embryo (usually at day 7 of development) into the uterus of a synchronized (in estrus 7 days prior to the transfer) recipient female that is typically not related to the embryo. Additionally, the development of

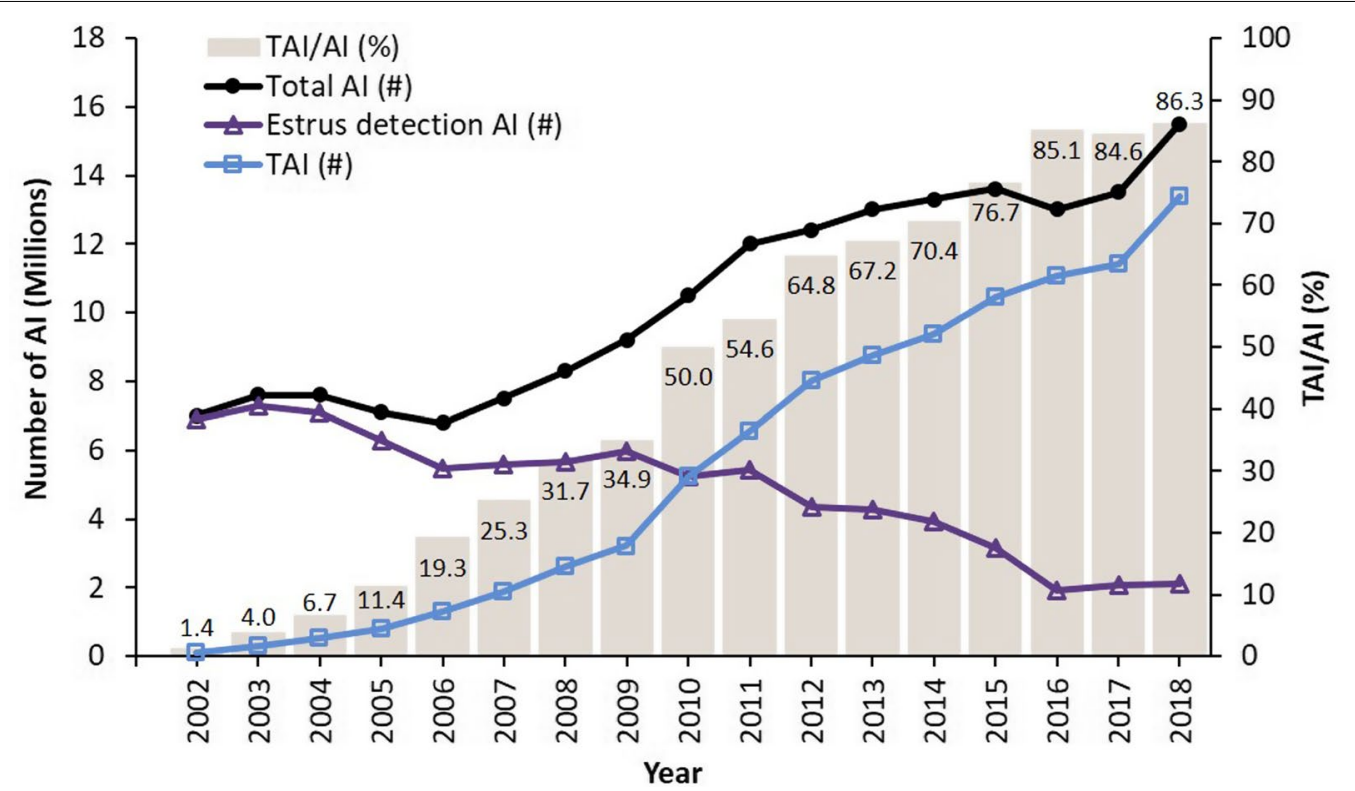

Fig. 2 Comparison of timed artificial insemination (TAI) and artificial insemination with estrous detection in cattle in Brazil from 2002 to 2018. Reproduced from Baruselli et al. (2019) under a CC-BY license 
synchronization techniques for timed embryo transfer (TET), has significantly increased the number of recipients suitable for receiving an embryo (Nasser et al. 2004). Historically, most embryos for ET were produced through MOET, also known as "flushing" or in vivo production. In a MOET program, a genetically superior donor female is typically superovulated prior to AI and then the resulting embryos are flushed from the uterus of the donor (i.e., genetic dam) 7 days after AI. Alternatively, embryos can be generated via IVP. In an IVP program, unfertilized oocytes are collected from the donor cow's ovaries by transvaginal, ultrasound-guided needle aspiration of multiple follicles per ovary, also known as OPU. The collected oocytes then undergo in vitro maturation (IVM), followed by in vitro fertilization (IVF) and then in vitro culture (IVC) for 7 days until they reach the blastocyst stage and are ready for cryopreservation or ET. IVP is advantageous because donors can be collected repeatedly for most of the year, even while pregnant, thereby keeping them in synchrony with an annual calving cycle. Furthermore, in a process known as juvenile in vitro ET (JIVET), oocytes for IVP can also be collected from prepubertal heifers ( $<7$ months old), but with decreasing embryo development rates at younger ages (Brogliatti and Adams 1996; Duby et al. 1996; Torres et al. 2014). Using JIVET could decrease the female generation interval to one year (Duby et al. 1996; Granleese et al. 2015).

Globally, the number of IVP embryos has increased dramatically overtime (Fig. 3). This increase has occurred predominately in North and South America and to a lesser extent in Europe, with almost no uptake of this technology in Asia and Africa. World-wide, more than one million bovine IVP embryos were produced in 2018 and 742,908 were transferred, of which more than $50 \%$ were transferred in South America. In Brazil specifically, over 270,000 IVP embryos were transferred in 2018. Baruselli et al. (2019) concluded that the uptake of reproductive biotechnologies in Brazil "increases productivity per unit of land and significantly contributes to improve the efficiency of livestock. Therefore, with the intensification of the use of reproductive biotechnologies it is possible to enhance production with reduced environmental impact." The challenge to continued adoption of these technologies is, according to these authors, dependent on an increase in extension services for producers and specialists, development of more efficient/cost-effective products and practical protocols, increased integration between universities, research institutes, veterinarians and industry, and market demand for the production of animal protein with higher quality, efficiency and environmental and economic sustainability (Baruselli et al. 2019).

Another way to increase selection intensity is through embryo multiplication procedures, including embryo splitting and cloning by embryonic cell NT (ECNT) (Heyman et al. 1998; Lopes et al. 2001). Alternatively, adult somatic cell NT (SCNT) cloning can be used to multiply unique genotypes (Oback and Wells 2003; Wilmut et al. 1997). Unfortunately, due to faulty or incomplete epigenetic reprogramming of the donor cell genome, SCNT cloning often results in high rates of

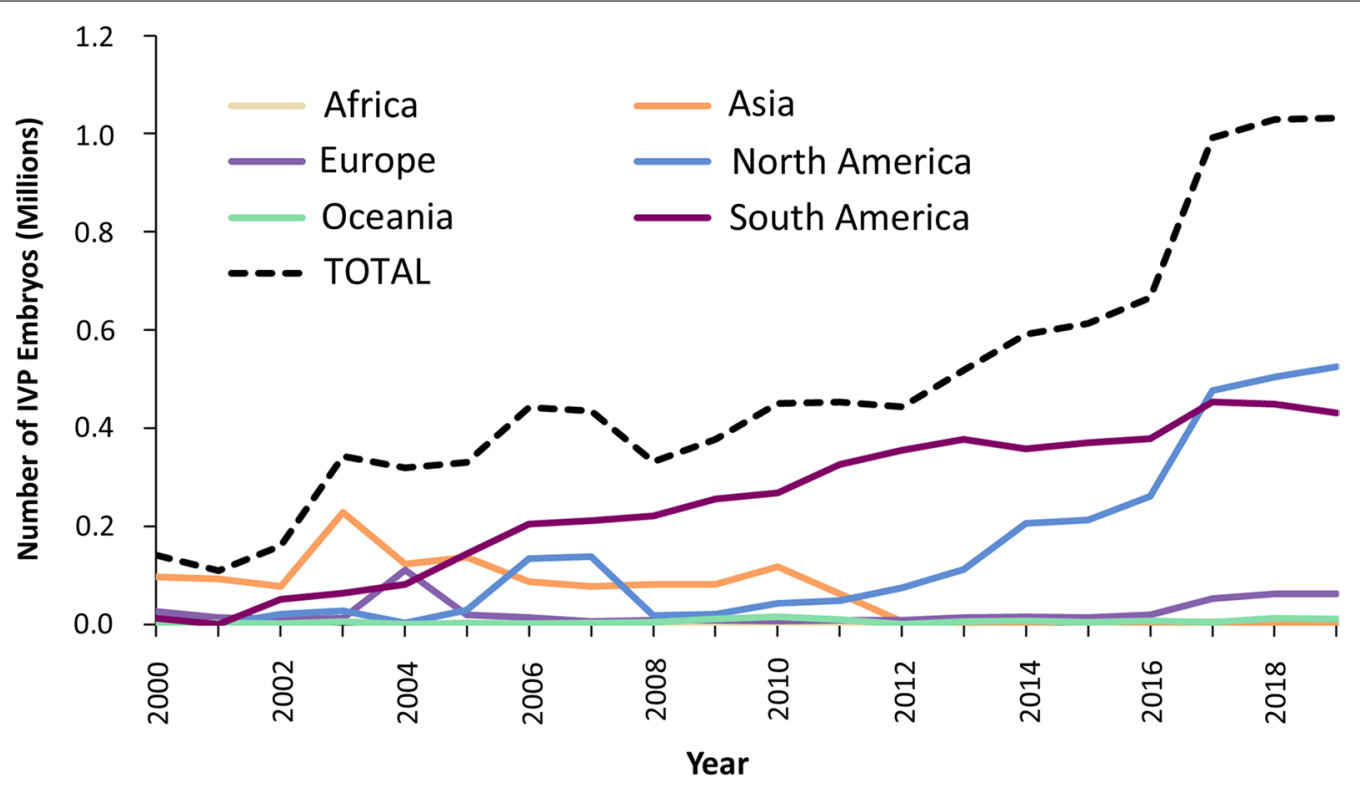

Fig. 3 Number of in vitro produced (IVP) bovine embryos from 2000 to 2019, by continent. Data from IETS (2000-2019) Data Retrieval Committee Reports 
pregnancy loss and can also negatively affect the viability of live-born calves (Akagi et al. 2013; Galli and Lazzari 2021; Keefer 2015). Therefore, SCNT cloning is primarily used for research or to produce "back-ups" of individual animals with unique genetic features (Bousquet and Blondin 2004; Loi et al. 2016). On the other hand, ECNT cloning has been shown to greatly reduce the incidence and severity of abnormal phenotypes compared to somatic clones, but has limited multiplication potential due to the small number of embryonic cells, or blastomeres (Heyman et al. 2002; McLean et al. 2020; MisicaTurner et al. 2007).

One advanced reproductive biotechnology that has been invaluable for rodent and primate research, but until recently was not available for livestock species, is embryonic stem cells (ESCs) (Blomberg and Telugu 2012; Evans and Kaufman 1981; Ezashi et al. 2016; Li et al. 2008; Soto and Ross 2016). ESCs are derived from the inner cell mass (ICM) of preimplantation blastocysts. The ICM is the tight cluster of cells inside a blastocyst that will eventually give rise to the definitive structures of the fetus. ESCs are a unique cell type because they are self-renewing (able to replicate indefinitely) and pluripotent, meaning they can differentiate into all three primary germ layers: ectoderm, endoderm, and mesoderm (Wu and Belmonte 2015; Ying et al. 2008). Given that ESCs are derived from pre-implantation embryos, they could provide a potentially unlimited source of elite genetics from the next generation of animals for multiplication, which could further increase the selection intensity of both males and females in livestock production.

Unfortunately, derivation and stable propagation of pluripotent ESCs from domestic ungulates, including cattle, has been challenging (Blomberg and Telugu 2012; Ezashi et al. 2016; Soto and Ross 2016). Although there have been reports of the development of bovine ESC lines, they did not pass the standard pluripotency tests (i.e., in vitro embryoid body formation, in vivo teratoma assay, and/or chimera formation). Moreover, they showed poor derivation efficiencies, limited proliferation capacities, and loss of pluripotency markers after extensive passages (Kim et al. 2017; Saito et al. 1992). Consequently, cattle research has been limited to investigation of induced pluripotent stem cells (iPSC), which can be derived from the epigenetic reprogramming of somatic cells (Heo et al. 2015; Kawaguchi et al. 2015).

However, in 2018, after decades of research, Bogliotti et al. (2018) reported the successful derivation of pluripotent bovine ESCs with stable morphology, transcriptome, karyotype, population-doubling time, pluripotency marker gene expression, and epigenetic features. Moreover, the authors reported that stable bovine ESCs can be established quickly in 3-4 weeks and were simply propagated by trypsin treatment (Bogliotti et al. 2018). More recently, Zhao et al. (2021) reported the successful derivation of another type of bovine pluripotent stem cell, expanded potential stem cells (EPSCs). Currently, the production of a live calf from ESCs would require NT using an ESC as the nuclear donor. Experiments have shown that ESC-NT results in similar blastocyst development rates to SCNT, but there could potentially be higher pregnancy rates and less offspring abnormalities (Bogliotti et al. 2018; McLean et al. 2020; Zhao et al. 2021).

In the future, ESCs could enable in vitro breeding (IVB) schemes, which could drastically decrease the generation interval (Goszczynski et al. 2018). IVB would involve repeated cycles of deriving gametes (i.e., sperm and eggs) in culture from ESCs and IVF (Goszczynski et al. 2018). In mice, ESCs have been induced in culture to become primordial germ cell-like cells (PGCLCs) and subsequently induced to form gametes. Furthermore, these in vitro gametes have successfully produced live, fertile offspring (Hayashi et al. 2011, 2012; Ishikura et al. 2016; Yoshino et al. 2021). Although bovine PGCLCs have yet to be produced, the ability to derive bovine ESCs now makes this strategy possible (Goszczynski et al. 2018). However, IVB will only be a useful tool to improve genetic gain if combined with GS (see discussion below).

\section{Synergistic power of GS \& ART}

When GS and ART are used concurrently, the benefits of each act synergistically to accurately select genetically superior, young animals, thereby substantially reducing the generation interval and accelerating rates of genetic gain (Fig. 1) (Granleese et al. 2015; Kadarmideen et al. 2015; Loi et al. 2016). For example, GS can be used to accurately select high-genetic-merit young donor females for MOET or IVP and bulls for semen collection. The embryos produced from these matings will also have high genetic merit. However, due to Mendelian sampling variance, not all full-sibling embryos have the same genetic merit and there is a large cost and natural resource drain in gestating ET calves of unknown genetic merit only to later cull the genetically inferior animals (Segelke et al. 2014). Therefore, methods to produce and identify genetically superior embryos before ET have been highly sought after.

The idea of combining GS with the manipulation of sex cells and embryos to accelerate genetic gain, coined "velogenetics," was first proposed by Georges and Massey (1991). Briefly, velogenetics is a breeding scheme based on the collection of fetal oocytes for IVP followed by genomic testing of the resulting embryos, with the possibility to reduce the generation interval to 3-6 months (Georges and Massey 1991). Although this scheme would 
provide a substantial decrease in the generation interval, the low efficiency and practical complications of having to slaughter the dam for fetal collection, have inhibited further development of this specific scheme (Chohan and Hunter, 2004; Figueiredo et al., 1993). However, alternative approaches with the same goals have been developed.

Genomic screening of embryos (GSE), sometimes referred to as embryo genotyping, is the process of genotyping cells collected from a biopsy of a preimplantation embryo (i.e., before ET into a recipient female). GSE can be used to predict an embryo's genetic merit so that only the embryos with the highest genetic merit are used for ET. Moreover, since a larger number of embryos can be generated via IVP compared to live-born animals, GSE can be used to select a small number of animals (in their embryo stage) from a large pool of candidates for ET, which will further increase the selection intensity (Fisher et al. 2012; Kadarmideen et al. 2015; Yudin et al. 2016). Although GSE holds great potential, there are currently several technical limitations to overcome.

There is an inverse relationship between the viability of a biopsied embryo and the ability to obtain enough DNA sufficient for genotyping (Ponsart et al. 2013). DNA extracted from embryo biopsies can be used for genetic diagnosis [i.e., genotyping of a few specific loci via polymerase chain reaction (PCR)], for GS, or a combination of both. DNA from one to several biopsied cells has been used successfully for genetic diagnosis (primarily, sex identification) of preimplantation bovine embryos (Cenariu et al. 2012; de Sousa et al. 2017; Ponsart et al. 2013; Tominaga and Hamada 2004). Moreover, de Sousa et al. (2017) took biopsies of a limited number of cells (10-20 blastomeres) from the trophectoderm of both in vivo derived and IVP bovine embryos on day 7 of development. They demonstrated that the biopsies were sufficient for embryo sexing via PCR and that there was no significant $(\mathrm{P}>0.05)$ difference on day 60 pregnancy rates of fresh transfer, biopsied embryos compared to control, non-biopsied embryos. It is important to note that this study did not investigate pregnancy rates of embryos that had been both biopsied and cryopreserved. Due to the limited amount of time between being able to biopsy an embryo and needing to transfer the fresh embryo (i.e., both on day 7 of IVP development), the ability to cryopreserve biopsied embryos will likely be a critical process for applying GSE on a commercial scale (Mullaart and Wells 2018).

While embryo biopsies for sex determination have been routinely used in ET programs (Bondioli 1992; Lopes et al. 2001; Ponsart et al. 2013), GS of embryos has been limited since a much larger number of cells (minimum of 30-40 cells) must be biopsied and genotyped to make accurate selection decisions (Fisher et al. 2012;
Ponsart et al. 2013). Although taking a biopsy of more than $\sim 20$ cells will drastically decrease embryo viability, alternatives to generate a sufficient amount of DNA for GS from only a small number of biopsied cells have been investigated, such as growing biopsied cells in culture (Ramos-Ibeas et al. 2014; Shojaei Saadi et al. 2014), and using whole genome amplification of biopsied cells in combination with imputation from known parental and population genotypes (Allan 2019; Lauri et al. 2013; Shojaei Saadi et al. 2014).

An adaption to traditional GSE was developed by Kasinathan et al. (2015) to genomically screen unborn bovine fetuses rather than embryos. Their strategy utilized multiple ET's and subsequent embryo flushing (21-26 day fetuses) to generate fetal fibroblast lines. DNA was extracted from the fibroblast lines for GS and the resulting GEBVs for NM\$ (U.S. dairy) were used to select the line with the highest genetic merit. Cells from the selected elite fibroblast line were used as donor cells for SCNT cloning. Following ET of the cloned embryos, five healthy calves with elite dairy genetics were born (Kasinathan et al. 2015). While this scheme overcomes the challenges of taking embryo biopsies for GS, it still relies on the inefficient process of SCNT cloning to produce live offspring (Akagi et al. 2013; Keefer 2015).

Bovine pluripotent stem cells (Bogliotti et al. 2018; Zhao et al. 2021) have the potential to open a whole new avenue for GSE. Given that pluripotent stem cells are selfreplicating, a sufficient amount of DNA could be extracted without harming the viability of the remaining stem cells, which would allow for the use of GS to determine the genetic merit of each line. The genetically superior stem cell lines could then be used for ECNT, similar to the Kasinathan et al. (2015) method. Alternatively, the genetically superior stem cell lines could be in vitro differentiated (as described above) to produce gametes which would enable IVB schemes (Goszczynski et al. 2018). Goszczynski et al. (2018) anticipates that one round of IVB could be completed in 3-4 months, which would drastically reduce the generation interval. These authors estimate that in the same time that it takes a GS program to obtain its first generation (2.5 years), an IVB program would instead allow 10 generations of mating and selection in this same period, ultimately enabling substantial genetic improvements to be made in a short amount time (Goszczynski et al. 2018).

\section{Gene editing (GnEd) potential}

A potentially ground-breaking tool for genetic improvement is GnEd, which offers promising opportunities to inactivate targeted gene function (i.e., knockout genes), knock-in genes from other species, and achieve intraspecies allele introgression in the absence of undesired linkage drag. GnEd refers to the use of site-directed nucleases 
to precisely introduce DSB at predetermined locations in the genome (Gaj et al. 2013). Cells have evolved two primary pathways to repair DSBs: non-homologous end joining (NHEJ) and homology-directed repair (HDR). The underlying principle is that the cell's endogenous repair factors will identify and congregate at the site of the DSB to repair the DNA in an efficient manner.

When using the NHEJ pathway, the cell's natural DNA repair pathway fuses the broken DNA ends back together through blunt-end ligation. NHEJ is referred to as "nonhomologous" because the ligation occurs without the use of a homologous nucleic acid template (e.g., sister chromatid) (Moore and Haber 1996). Consequently, this pathway is error-prone and often introduces variable-length insertion and deletion mutations (indels) at the DSB site (Sander and Joung 2014). In other words, the NHEJ pathway allows for the efficient disruption or knockout of a gene by targeting breaks to the coding region of the gene, where indels can result in frameshift or nonsense mutations.

On the other hand, the cell can use the HDR pathway if a nucleic acid donor template is provided. HDR templates can be designed to include desired modifications between regions of homology flanking either side of the targeted DSB, and templates are generally provided to the cell in the form of single-stranded or double-stranded DNA. The cell's DNA repair enzymes can use the template as a model for precise repair by homologous recombination. The HDR pathway can be used to introduce, or knock-in, a range of gene edits, from point mutations to allelic substitutions, to entire transgenes (Sander and Joung 2014). However, in most cell types a lower frequency of HDR than NHEJ has been observed (Sonoda et al. 2006).

There are currently three primary site-directed nucleases used for GnEd in livestock: (1) zinc finger nucleases (ZFN); (2) transcription activator-like effector nucleases (TALENs); and (3) clustered regularly interspersed short palindromic repeats and associated protein 9 (CRISPR/ Cas9). Since 2012, all three GnEd systems have been used to perform both gene knockouts and knock-ins in livestock cells and zygotes (Bishop and Van Eenennaam 2020; Tait-Burkard et al. 2018; Tan et al. 2016). Most recently, the high efficiency, technical simplicity of design, and cost-effectiveness of the CRISPR/Cas9 system has greatly advanced the potential for GnEd in livestock (Petersen 2017).

GnEd experiments in cattle have primarily focused on three main areas of improvement (1) animal health and welfare, (2) product yield or quality, and (3) reproduction or novel breeding schemes (Table 1). All three of these areas are highly aligned with the goals of conventional breeding programs (Rexroad et al. 2019; Tait-Burkard et al. 2018; Van Eenennaam 2017).

In particular, a highly anticipated application of GnEd in livestock is to enable breeders to tackle animal health and welfare issues at a genetic level in a way that is either not currently possible, or would result in decreased rates of genetic gain, if pursued through conventional breeding. For example, GnEd enabled Wu et al. (2015) and Gao et al. (2017) to precisely insert genes from other species (mouse Sp110 (SP110 Nuclear Body Protein) and human NRAMP1 (Natural Resistance-Associated Macrophage Protein 1), respectively) into an intergenic region of the bovine genome to decrease susceptibility to tuberculosis. This scientific feat would not have been possible through conventional breeding methods alone. GnEd has also enabled researchers to replicate a beneficial mutation in the prolactin receptor $(P R L R)$ gene, first found in Senepol cattle and hypothesized to result in a SLICK phenotype (i.e., short, sleek hair coat), in Angus cattle to increase thermotolerance (Rodriguez-Villamil et al. 2021). Although the Senepol PRLR mutation could be introgressed into another breed, such as Angus, through conventional breeding methods alone, the process would require multiple generations of backcrossing to restore genetic merit to pre-introgression levels, due to linkage drag (Tan et al. 2012). In a species like cattle, with a long generation interval, backcrossing is a time-consuming and expensive process (Gaspa et al. 2015; Visscher et al. 1996). Additionally, it is important to note that genetic solutions for animal health and welfare issues are often more sustainable and require less labor for livestock producers than chemical or mechanical methods (e.g., polled genetics versus dehorning) (Gottardo et al. 2011; Thompson et al. 2017). It is also anticipated that GnEd could be used to repair defective genes, such as recessive lethal or heritable disease variations in high genetic merit animals (Ikeda et al. 2017; Ishino et al. 2018).

Overall, the potential for GnEd to improve livestock sustainability is clearly evident. As illustrated by the 2018 National Academies of Sciences, Engineering, and Medicine (NASEM) study, "Science Breakthroughs 2030: A Strategy for Food and Agricultural Research", which identified "the ability to carry out routine gene editing of agriculturally important organisms" as one of the five most promising scientific breakthroughs that are possible to achieve in the next decade to increase the U.S. food and agriculture system's sustainability, competitiveness, and resilience (NASEM 2018). However, strategies for routinely incorporating GnEd into existing animal breeding programs, especially for species with long-generation intervals, like cattle, are less evident. 
Table 1. Publications using gene editing in cattle for agricultural applications, grouped by category of genetic improvement goals.

\begin{tabular}{|c|c|c|c|c|c|}
\hline Goal & Genome target and function & Editing approach & Editor $^{a}$ & Live edited offspring & Reference(s) \\
\hline \multicolumn{6}{|l|}{ Animal health/welfare } \\
\hline \multirow[t]{2}{*}{ Prevent horn growth } & \multirow[t]{2}{*}{ Horn/Poll } & $\begin{array}{l}\text { Replaced bovine horned } \\
\text { allele }(p) \text { with bovine } \\
\text { POLLED, Celtic allele }\left(P_{C}\right)\end{array}$ & TALEN & Yes & $\begin{array}{l}\text { Carlson et al. (2016), Tan } \\
\text { et al. (2013) }\end{array}$ \\
\hline & & $\begin{array}{l}\text { Generated deletions in } \\
\text { the horned loci }\end{array}$ & CRISPR/Cas9 & No & Hennig et al. $(2021 a, b)$ \\
\hline \multirow[t]{2}{*}{$\begin{array}{l}\text { Disease resistance: } \\
\text { Mastitis }\end{array}$} & \multirow[t]{2}{*}{$\begin{array}{l}\text { CSN2 (Beta-Casein): milk protein } \\
\text { gene }\end{array}$} & $\begin{array}{l}\text { Inserted Staphylococcal } \\
\text { lysostaphin (antimicrobial) } \\
\text { gene }\end{array}$ & ZFN & Yes & Liu et al. (2013) \\
\hline & & $\begin{array}{l}\text { Inserted human lysozyme } \\
\text { (antimicrobial) gene }\end{array}$ & ZFN & Yes & Liu et al. (2014) \\
\hline \multirow[t]{2}{*}{$\begin{array}{l}\text { Disease resistance: Tuber- } \\
\text { culosis }\end{array}$} & $\begin{array}{l}\text { ITGB2 Intergenic region } \\
\text { between SFTPA1 (Surfactant } \\
\text { Protein A1) and MAT1A } \\
\text { (Methionine Adenosyltrans- } \\
\text { ferase 1A) }\end{array}$ & $\begin{array}{l}\text { Inserted mouse Sp110 } \\
\text { (SP110 Nuclear Body } \\
\text { Protein) gene }\end{array}$ & TALEN & Yes & Wu et al. (2015) \\
\hline & $\begin{array}{l}\text { Intergenic region } \\
\text { between FSCN1 (Fascin Actin- } \\
\text { Bundling Protein 1) and ACTB } \\
\text { (Actin Beta) }\end{array}$ & $\begin{array}{l}\text { Inserted human NRAMP1 } \\
\text { (Natural Resistance- } \\
\text { Associated Macrophage } \\
\text { Protein 1) gene (controls } \\
\text { Tuberculosis infections) }\end{array}$ & CRISPR/Cas9 & Yes & Gao et al. (2017) \\
\hline Disease resistance: BRD & $\begin{array}{l}\text { (Integrin Subunit Beta 2): } \\
\text { encodes the leukocyte signal } \\
\text { peptide CD18 }\end{array}$ & $\begin{array}{l}\text { Substituted glycine in } \\
\text { place of glutamine to } \\
\text { cause cleavage of CD18 }\end{array}$ & ZFN & No & Shanthalingam et al. (2016) \\
\hline \multirow[t]{3}{*}{ Disease resistance: BSE } & \multirow{3}{*}{$\begin{array}{l}\text { PRNP (Prion Protein): suscepti- } \\
\text { bility to BSE }\end{array}$} & Disrupted the PRNP gene & TALEN & No & Choi et al. (2015) \\
\hline & & & CRISPR/Cas9 & No & Bevacqua et al. (2016) \\
\hline & & $\begin{array}{l}\text { Substituted valine in place } \\
\text { of glycine at position } 127 \\
\text { to confer resistance }\end{array}$ & CRISPR/Cas9 & Yes & Park et al. (2020) \\
\hline $\begin{array}{l}\text { Repair mutation: IARS } \\
\text { syndrome }\end{array}$ & IARS & $\begin{array}{l}\text { Substituted a single } \\
\text { base pair to correct the } \\
\text { mutation }\end{array}$ & CRISPR/Cas9 & Yes & $\begin{array}{l}\text { Ikeda et al. (2017), Ishino } \\
\text { et al. (2018) }\end{array}$ \\
\hline \multirow[t]{2}{*}{ Thermo tolerance } & $\begin{array}{l}\text { PMEL (Premelanosomal Protein): } \\
\text { coat color }\end{array}$ & $\begin{array}{l}\text { Introduced a } 3 \text { bp } \\
\text { deletion associated } \\
\text { with diluted, or silver, } \\
\text { coat-color }\end{array}$ & CRISPR/Cas9 & Yes & Laible et al. (2020) \\
\hline & $\begin{array}{l}\text { PRLR (Prolactin Receptor): hair } \\
\text { coat length }\end{array}$ & $\begin{array}{l}\text { Disrupted PRLR gene } \\
\text { to generate a SLICK } \\
\text { (short, sleek hair coat) } \\
\text { phenotype }\end{array}$ & CRISPR/Cas9 & Yes & $\begin{array}{l}\text { Rodriguez-Villamil et al. } \\
\text { (2021) }\end{array}$ \\
\hline \multicolumn{6}{|l|}{ Product yield or quality } \\
\hline \multirow[t]{4}{*}{ Eliminate a milk allergen } & \multirow{3}{*}{$\begin{array}{l}\text { BLG (Beta-Lactoglobulin): whey } \\
\text { protein gene }\end{array}$} & Disrupted the $B L G$ gene & ZFN & Yes & Yu et al. (2011) \\
\hline & & \multirow{2}{*}{$\begin{array}{l}\text { Disrupted the BLG gene } \\
\text { by inserting } 5 \text { bp with } \\
\text { single stranded oligonu- } \\
\text { cleotide template }\end{array}$} & ZFN or TALEN & No & Wei et al. (2015) \\
\hline & & & TALEN & Yes & Wei et al. (2018) \\
\hline & CSN2: milk protein gene & $\begin{array}{l}\text { Inserted LacS gene } \\
\text { (sulfolobus solfataricus } \\
\text { beta-glycosidase) to } \\
\text { digest lactose }\end{array}$ & TALEN & Yes & Su et al. (2018) \\
\hline \multirow[t]{4}{*}{ Increase lean muscle yield } & \multirow{4}{*}{$\begin{array}{l}\text { MSTN (Myostatin): negative } \\
\text { regulator of muscle growth }\end{array}$} & \multirow[t]{4}{*}{ Disrupted the MSTN gene } & TALEN & No & Carlson et al. (2012) \\
\hline & & & ZFN & Yes & Luo et al. (2014) \\
\hline & & & TALEN & Yes & Proudfoot et al. (2015) \\
\hline & & & CRISPR/Cas9 & No & Namula et al. (2019) \\
\hline \multicolumn{6}{|c|}{ Reproduction and novel breeding schemes } \\
\hline $\begin{array}{l}\text { Generate host for germ } \\
\text { cell transfer }\end{array}$ & $\begin{array}{l}\text { NANOS2 (Nanos C2HC-Type } \\
\text { Zinc Finger 2): necessary for } \\
\text { male germline development }\end{array}$ & $\begin{array}{l}\text { Disrupted the NANOS2 } \\
\text { gene to eliminate germ } \\
\text { cell production }\end{array}$ & CRISPR/Cas9 & Yes & $\begin{array}{l}\text { Ciccarelli et al. (2020), Miao } \\
\text { et al. (2019) }\end{array}$ \\
\hline
\end{tabular}


Table 1. (continued)

\begin{tabular}{|c|c|c|c|c|c|}
\hline Goal & Genome target and function & Editing approach & Editor $^{\mathrm{a}}$ & Live edited offspring & Reference(s) \\
\hline $\begin{array}{l}\text { Increased frequency of } \\
\text { male offspring }\end{array}$ & Safe harbor loci, H11 & $\begin{array}{l}\text { Inserted an additional } \\
\text { copy of the bovine SRY } \\
\text { (Sex Determining Region } \\
\text { Y protein) gene }\end{array}$ & CRISPR/Cas9 & Yes & Owen et al. (2021) \\
\hline
\end{tabular}

a Editor: zinc finger nucleases (ZFN), transcription activator-like effector nucleases (TALENs), and clustered regularly interspersed short palindromic repeats (CRISPR)associated protein 9 (Cas9). Note: BRD, bovine respiratory disease; BSE, bovine spongiform encephalopathy; IARS, Isoleucyl-tRNA synthetase

\section{ART enables production of live GnEd offspring}

For GnEd to be an important factor for genetic improvement, it must reliably edit the germline of breeding stock, so the edits can be passed on to the next generation. To date, it has been challenging to produce live, homozygous, non-mosaic, GnEd offspring. There are currently two primary methods to generate GnEd bovine embryos and each has associated tradeoffs (Fig. 4).

One option is to introduce the GnEd reagents (e.g., CRISPR/Cas9) into a somatic cell line and subsequently clone the cell line by SCNT to produce embryos. Thus far, SCNT has been the primary method for producing $\mathrm{GnEd}$ livestock because the clonal colony growth of cell lines provides large amounts of DNA that can be genomically sequenced to confirm and isolate cells with the desired edit such as to only produce animals with intended edits. However, as previously discussed, SCNT cloning often results in high rates of pregnancy loss and can also negatively affect the viability of live-born calves (Akagi et al. 2013; Keefer 2015). Additionally, unless a scheme similar to Kasinathan et al. (2015) is used, adult somatic cloning increases the generation interval by one generation (equivalent to two years in cattle), compared to ET of in vivo derived or IVP embryos.

Alternatively, GnEd reagents can be introduced directly into the cytoplasm of an IVP zygote, typically via microinjection or more recently, via electroporation (Lin and Van Eenennaam 2021; McLean et al. 2020). GnEd of zygotes is an attractive option because it avoids the inefficiencies associated with SCNT cloning, does not increase the generation interval because the GnEd process is occurring in the next generation of animals, and allows for the introduction of GnEd reagents into a genetically diverse population of foundation animals as each zygote will produce a genetically distinct animal, as compared to animals derived from a clonal cell line. However, characterizing GnEd zygotes is difficult due to the challenges of GSE discussed above. Specifically, a major challenge associated with $\mathrm{GnEd}$ of zygotes is the production of mosaic animals (Bishop and Van Eenennaam 2020; Hennig et al. 2020; McLean et al. 2020). Mosaicism arises from mutations that occur after DNA replication (van Echten-Arends et al. 2011), resulting in one individual having two or more different genotypes. It is important to keep in mind that many livestock GnEd applications require homozygous modifications (i.e., two copies) to ensure inheritance of one copy in the F1 generation (Bishop and Van Eenennaam 2020). Therefore, mosaic GnEd animals will often require time-consuming and expensive subsequent crossbreeding to ultimately produce homozygous edited offspring (Fig. 4).

Regardless of the method used to generate GnEd bovine embryos, ET into synchronized recipient females is a crucial step in producing live GnEd offspring (Fig. 4). Therefore, GnEd in mammalian livestock species is currently reliant on the use of ART (i.e., IVP or SCNT to produce GnEd embryos, and ET to produce live, GnEd offspring).

\section{Synergistic strategies for incorporating GnEd into livestock breeding programs: Simulations}

To be an effective tool for genetic improvement, GnEd must integrate smoothly into existing cattle breeding programs (Bishop and Van Eenennaam 2020). Thus far, GnEd has not yet been applied at commercial scale, and so strategies for incorporating GnEd into livestock breeding programs have primarily been modeled via computer simulation.

One of the first simulation studies to explore the potential of combining GnEd with GS in a livestock breeding program was by Jenko et al. (2015). Although, GnEd is currently being used to improve monogenic traits, Jenko et al. (2015) modeled a hypothetical breeding scheme of GS supplemented with promotion of alleles by GnEd (PAGE) to improve a quantitative trait and compared the results to a baseline scenario of using GS alone. In the PAGE scheme, the top sires $(5,10$, or 25$)$ based on their true breeding values (i.e., GS with perfect accuracy) were selected and then GnEd for 1-100 loci. They found that using GS + PAGE for 20 loci using 25 sires doubled the rate of genetic gain as compared to using GS alone. It is important to note that this simulation assumed a quantitative trait that had 10,000 known quantitative trait nucleotides (QTN), but identifying such QTN is not a trivial exercise and to date relatively few QTN with large effects on quantitative traits have been identified (Georges et al. 2019). 


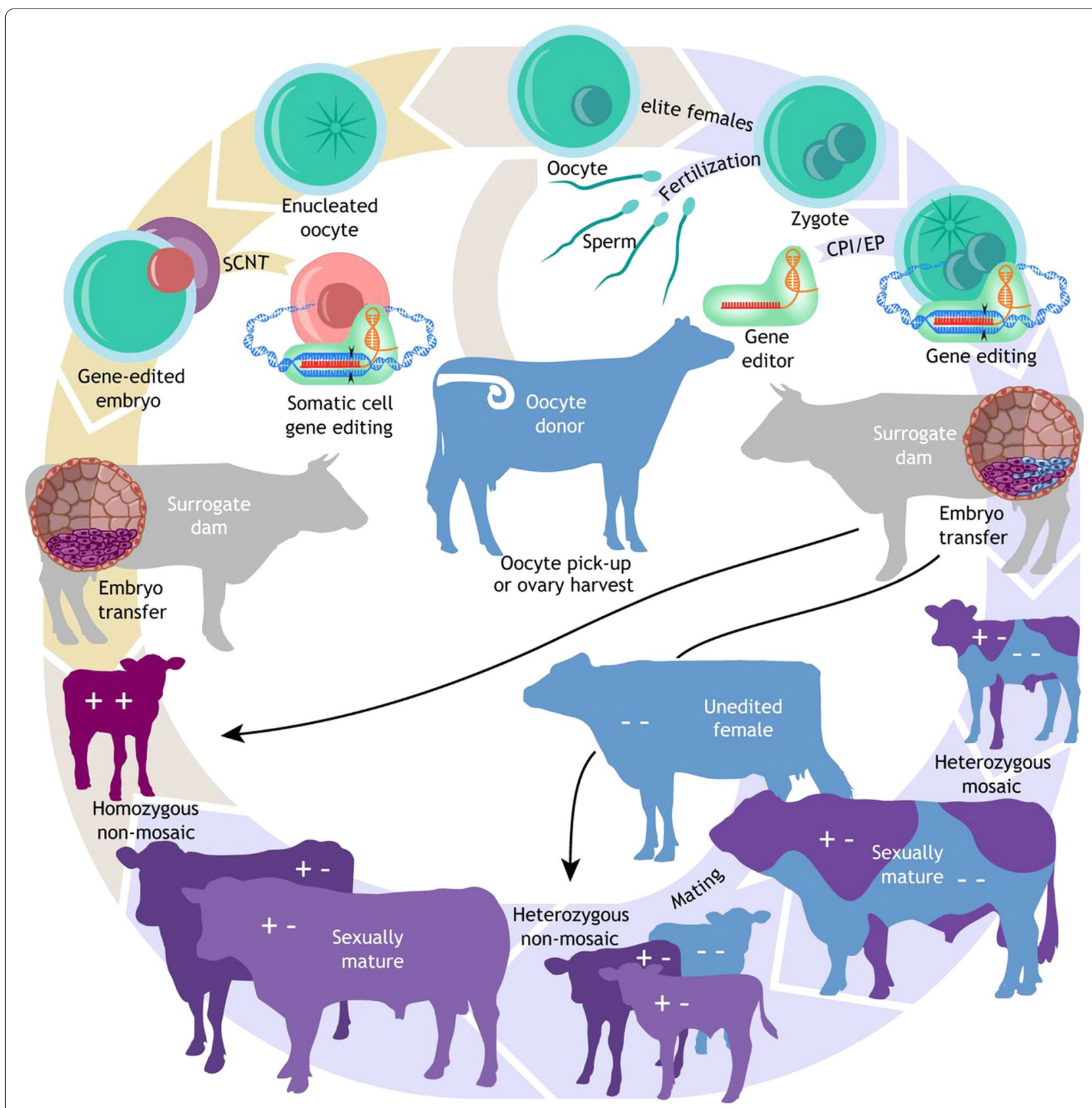

Fig. 4 Schematic showing the number of steps required to produce live, homozygous, non-mosaic, GnEd livestock (maroon calf) through either somatic cell nuclear transfer (SCNT) cloning (tan arrows) or zygote microinjection (light purple arrows). Both methods include gamete collection and maturation, introduction of the gene-editing (GnEd) reagents, and transfer of embryos into synchronized recipients (surrogate dams). For the SCNT cloning approach (tan arrows) GnEd reagents are introduced into a somatic cell line and then SCNT cloning is used to produce embryos for transfer. The GnEd cell line can be screened before cloning to ensure production of a homozygous, non-mosaic animal. For the zygote microinjection approach (light purple arrows) GnEd reagents are introduced directly into a zygote via cytoplasmic injection or electroporation. GnEd of zygotes can result in mosaic offspring, which requires subsequent breeding to produce first heterozygous and ultimately homozygous $\mathrm{GnEd}$ offspring. Therefore, gene editing of zygotes may require more steps to produce a homozygous, non-mosaic, GnEd animal, as indicated by the increased number of light purple arrows (7) compared to the number of tan arrows (3). Reproduced from (Bishop and Van Eenennaam 2020) under a CC-BY license 
Bastiaansen et al. (2018) modeled GnEd of a monogenic trait at the zygote stage in a generic livestock population combined with GS for a quantitative trait (i.e., indexbased selection). In this simulation, zygotes from either 0,10 , or $100 \%$ of matings from genomically-selected elite parents were GnEd for the desired monogenic trait. Additionally, due to the low efficiencies of GnEd reported in the literature (Tan et al. 2016), they modeled various GnEd success and embryo survival rates. When they modeled $100 \%$ GnEd efficiency and embryo survival, they observed a strong favorable impact of GnEd on decreasing the time to fixation for the desired allele (four-fold faster), compared to GS alone. However, when they modeled a $4 \%$ GnEd efficiency, this had a major impact on the number of GnEd procedures needed (increased by $72 \%)$ and the selection response for the polygenic trait decreased by eight-fold, compared to the $100 \%$ efficiency model (Bastiaansen et al. 2018). As discussed previously, GnEd of zygotes is typically not $100 \%$ and mosaic animals are common (Hennig et al. 2020; McLean et al. 2020). Therefore, in a commercial setting GnEd embryos will likely need to be biopsied to confirm the desired change before ET to avoid transferring embryos without the desired edit(s). Moreover, the current technical limitations of embryo biopsying will need to be overcome to not only identify embryos with the intended edit(s), but also to use GS to select embryos with superior genetic merit to increase rates of genetic gain.

Van Eenennaam (2017) proposed a scheme where GnEd could be incorporated as an added step to the Kasinathan et al. (2015) elite cattle production system (Fig. 5). This approach was modeled to introduce a beneficial, monogenic, dominant allele (i.e., the POLLED Celtic allele $\left(\mathrm{P}_{\mathrm{C}}\right)$ ) into the U.S. dairy cattle (Mueller et al. 2019) and northern Australian beef cattle populations (Mueller et al. 2021). In these simulations, fetal tissue from the next generation of yet-to-be-born bulls was genomically screened and selected, edited, and then successfully cloned such that this production system added 3-5 months to produce a homozygous GnEd bull (Fig. 5).

Mueller et al. (2019) modelled the U.S. dairy population and found that the use of GnEd was the most effective way to increase the frequency of the desired $P_{C}$ allele while minimizing detrimental effects on inbreeding and the rate of genetic gain based on an economic selection index $(\mathrm{NM} \$)$. They observed that GnEd only the top $1 \%$ of bull calves per year based on their index value while placing moderate selection pressure on the polled phenotype was sufficient to maintain the same or a better rate of genetic gain compared to conventional selection

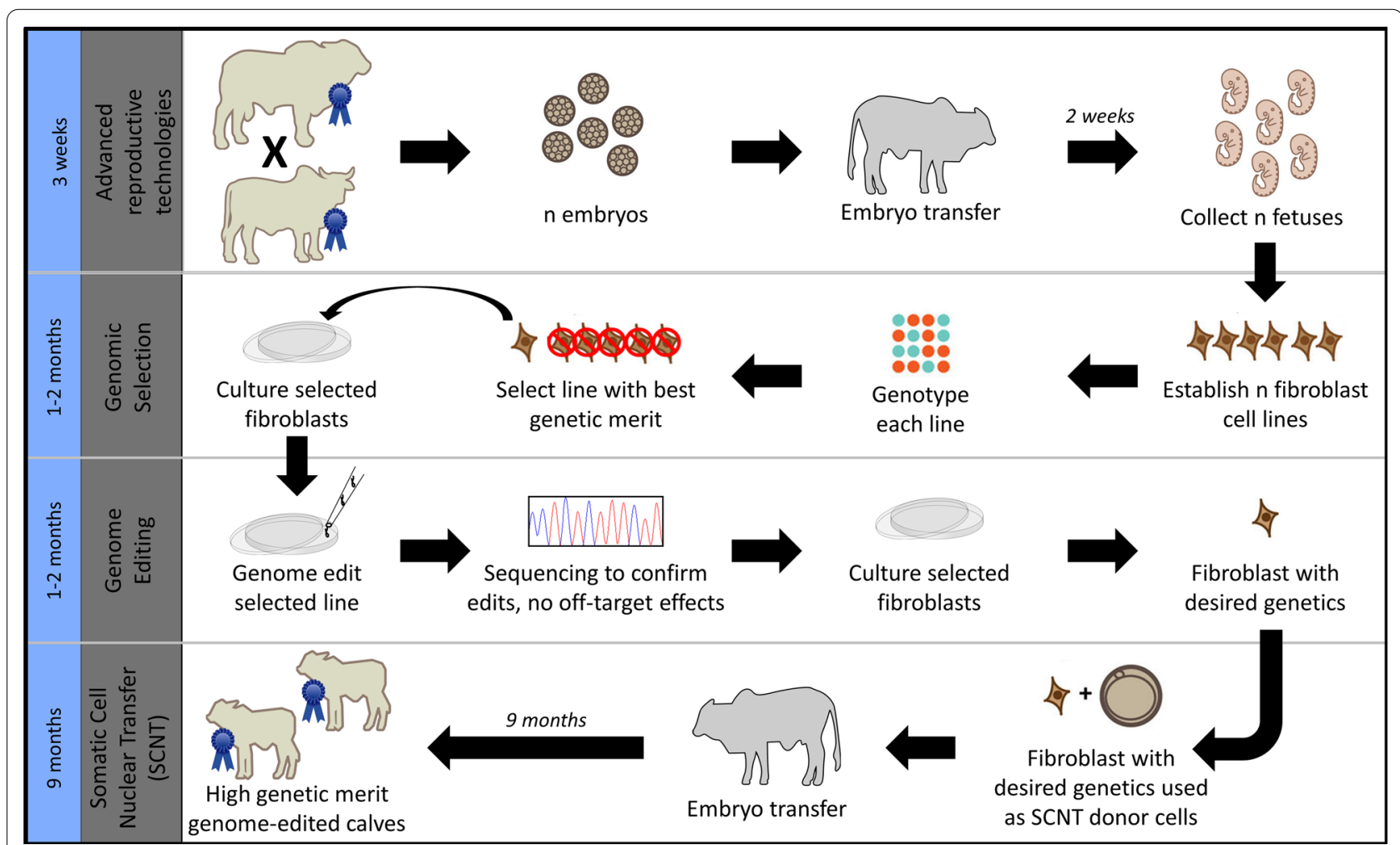

Fig. 5 Production of high genetic merit calves using a range of biotechnologies and showing where gene editing might fit into the process. Blue ribbons represent elite genetics. Modified from Van Eenennaam (2017) and reproduced from (Mueller et al. 2021) under a CC-BY license 
on genetic merit alone, while significantly increasing the $\mathrm{P}_{\mathrm{C}}$ allele frequency to greater than $90 \%$ (Mueller et al. 2019). Additionally, both Bastiaansen et al. (2018) and Mueller et al. (2019) found that GnEd reduced longterm inbreeding levels in scenarios that placed moderate to strong selection emphasis on the monogenic trait of interest (e.g., polled) compared to conventional breeding alone. Importantly, Mueller et al. (2019) modeled conventional breeding to represent the widespread use of AI in the U.S. dairy population (i.e., maximum of 5000 (5\%) matings/bull/year) (Capper and Cady 2019; Capper et al. 2009; García-Ruiz et al. 2016; VanRaden 2007), so a single dairy sire was able to have a large impact on the whole population. Therefore, only a small number of elite, GnEd polled, dairy sires were needed to see population-level results (Mueller et al. 2019).

In contrast, $\mathrm{AI}$ is rarely used in northern Australian beef cattle breeding herds ( $<1 \%)$ (MLA 2015), thus Mueller et al. (2021) modeled all matings via natural service (i.e., maximum of 35 matings/bull/year). The natural mating limits prevented individual GnEd beef bulls from having an extensive impact on the whole population. Consequently, GnEd only the top $1 \%$ of seedstock beef bull calves per year in mating schemes that placed moderate to strong selection on polled resulted in significantly slower rates of genetic gain as compared to conventional selection based on genetic merit alone. However, they did find that if the proportion of GnEd animals was increased to the top $10 \%$ of seedstock beef bull calves per year then similar rates of genetic gain could be achieved compared to conventional selection on genetic merit alone. In all scenarios, regardless of whether GnEd was applied, the population inbreeding level never exceeded $1 \%$. This level of inbreeding has been found to have relatively minor effects on traits of economic or biological significance in tropical beef cattle (Burrow 1998). This simulation study modeled solely natural mating because currently ARTs are scarcely used in this beef cattle population (MLA 2015). However, the authors explain that, "this is unlikely to be the situation with valuable GnEd bulls. It is more probable that a high-genetic-merit homozygous polled sire would be used for AI or IVP followed by ET, in the seedstock sector. This system would amplify the reach of each GnEd bull using well-proven ART and enable these bulls to produce hundreds or even thousands of progeny, and thus have a greater impact on the whole population."

Although Mueller et al. (2021) modeled a northern Australian beef cattle population, many findings are also applicable to the global beef industry and the situation in many developing countries (Baruselli et al. 2019; MLA 2015; Ojango et al. 2016a, b; Setiana et al. 2020; USDA 2020). AI is logistically challenging to implement for both smallholder farms in developing countries (e.g., lack of AI technicians and difficulties transporting cryopreserved semen) and often for commercial-scale extensive beef operations in developed countries (e.g., additional labor required to identify females in estrus and constrain them to perform AI). Therefore, a large number of GnEd natural service bulls would currently be needed to broadly disseminate GnEd traits globally in systems that have limited adoption of ARTs.

\section{Surrogate sires to disseminate GnEd traits}

A potential alternative to AI that could be enabled through GnEd is a concept called surrogate sires. Surrogate sires would be host bulls that carry germ cells from more genetically elite donor sires, and they will be able to pass on these desirable donor genetics through natural mating to improve production efficiency (Gottardo et al. 2019). Additionally, surrogate sire technology could potentially provide an efficient means for the distribution of traits that have been improved through GnEd (McFarlane et al. 2019).

It is anticipated that surrogate sire technology could be realized through germline complementation, which consists of using donor cells from one genetic background to complement or replace the germline of an otherwise sterile host of a different genetic background (Giassetti et al. 2019; Richardson et al. 2009). Germline complementation requires two components: (1) a host that lacks his own germline, but otherwise has normal gonadal development (e.g., intact reproductive tract), and (2) donor cells that are capable of becoming gametes (Fig. 6).

One method to generate germline-deficient hosts is via treatment with chemotoxic drugs (e.g., busulfan) or local irradiation, but these methods are not efficient in livestock because they either fail to completely eliminate the endogenous germline, or the treatment has undesirable

(See figure on next page.)

Fig. 6 Schematic of potential surrogate sire production systems. Grey represents steps to generate the host animal. Green and blue represent potential alternative sources and steps for generating donor cells. Light purple represents the germline complementation steps and dark purple/ maroon represents the resulting final surrogate sire product. Key differences are that in the green $(\mathbf{A})$ path, germline complementation would take place in a live, juvenile or adult, animal and the host would be non-mosaic. In contrast, in the blue path (B), germline complementation would take place at the embryo stage and the resulting host could be mosaic. Blue ribbons represent elite genetics and scissors represent steps that require (solid fill) gene editing or where gene editing could potentially be introduced (outline only). PGCLC: primordial germ cell-like cells, ESC: embryonic stem cell 


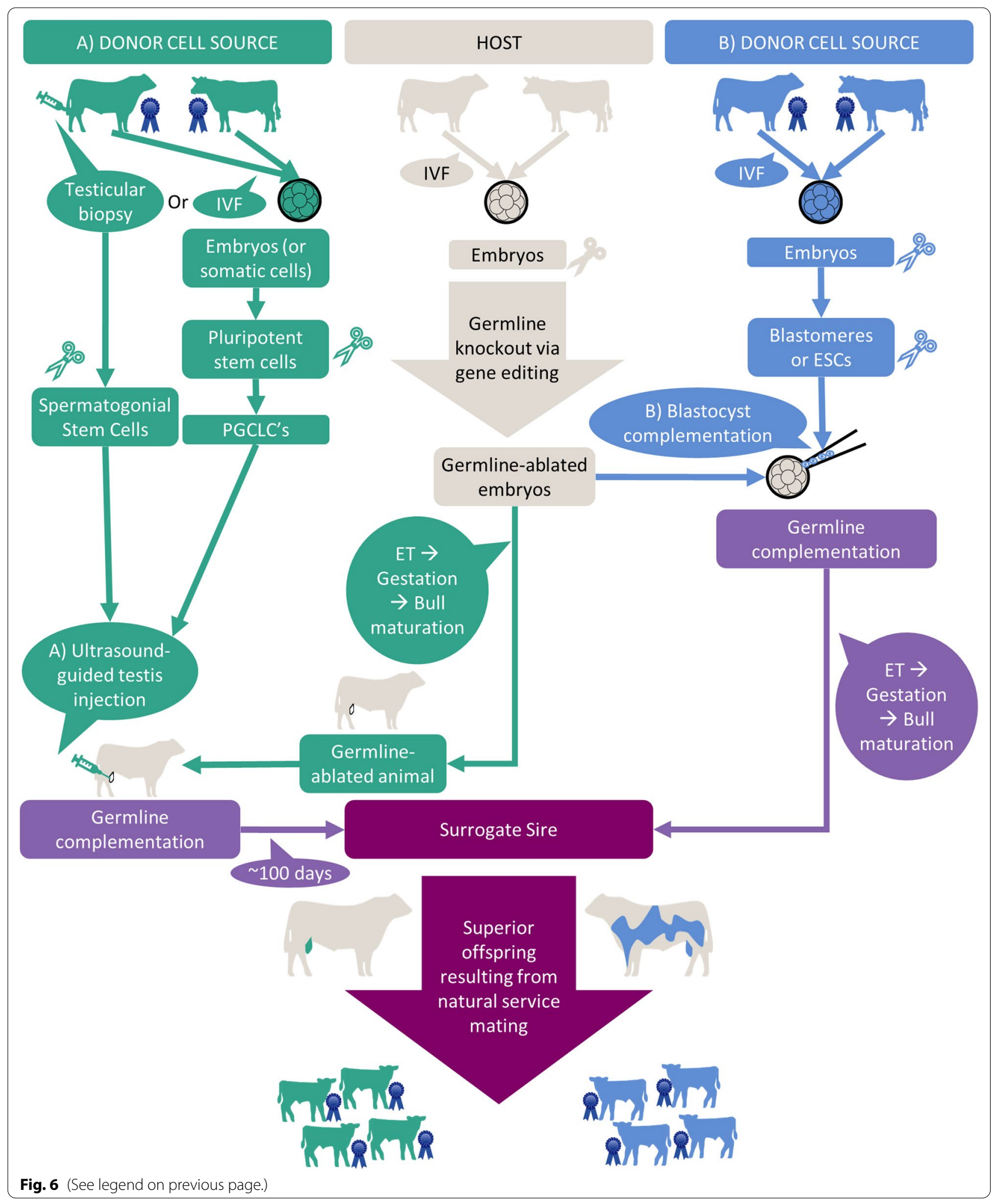


side effects on animal health (Giassetti et al. 2019). A promising alternative is to use GnEd to knockout a gene (e.g., NANOS2 or DAZL) in a zygote that is necessary for that animal's own germ cell production (Ciccarelli et al. 2020; McLean et al. 2021; Miao et al. 2019; Park et al. 2017; Taylor et al. 2017).

Donor cells could be blastomeres (i.e., embryo cells) or stem cells, as reviewed by Bishop and Van Eenennaam (2020) and McLean et al. (2020). Potential sources of germline competent stem cells are ESCs, iPSCs, or spermatogonial stem cells (SSCs), which can be isolated from mature or juvenile testes (Ciccarelli et al. 2020; Giassetti et al. 2019). Additionally, ESCs or iPSCs could possibly be induced in culture to become PGCLCs (Hayashi et al. 2011). Stem cells provide several advantages over blastomeres, as an embryo has a limited number of blastomeres and therefore a limited amount of genomic screening and multiplication potential (McLean et al. 2020). In contrast, stem cells are self-replicating so they can provide a potentially unlimited supply of donor cells. Additionally, stem cells could be GnEd in culture, possibly multiple times sequentially, and then DNA could be extracted without harming the viability of the remaining stem cells to both confirm the intended gene edit was made and to use GS to determine the genetic merit of each line. This scheme would be especially useful when applied to ESCs, which represent the next generation, to overcome the current challenges associated with GSE and to avoid the mosaicism issues currently associated with zygote GnEd.

The process of germline complementation (i.e., combining donor cells with a host) can occur at different stages of a host animal's development, depending on the donor cell source (Fig. 6). If the donor cells are SSCs or PGCLCs then they can be injected into a juvenile or adult host's germline-deficient gonad (Fig. 6A). SSCs transfer has been demonstrated in pigs and goats and represents germline cloning of the current generation of sires (Ciccarelli et al. 2020; Park et al. 2017). Whereas, PGCLCs derived from ESCs would represent germline cloning of the next generation since the donor cells would originate from an unborn 7-day old embryo. Alternatively, donor blastomeres or ESCs, which both represent the next generation, could be combined with the host at the developing embryo stage (Fig. 6B) (Ideta et al. 2016; McLean et al. 2020).

Irrespective of the production method, surrogate sires could unlock an opportunity to both accelerate rates of genetic gain and widely distribute traits improved via GnEd. The selection of only elite males for donor cells would increase selection intensity. Additionally, since the use of surrogate sires will not require any additional labor for commercial producers, there could be widespread adoption of this technology, which would dramatically reduce the lag in genetic merit that typically exists between the seedstock sector and the commercial sector. For example, Gottardo et al. (2019) performed simulations to develop and test a strategy for exploiting surrogate sire technology in a pig breeding programs. Their model projected that using surrogate sire technology in the swine industry would significantly raise the genetic merit of commercial sires by closing the typical 4 year genetic lag (difference in genetic mean between the nucleus and commercial populations), resulting in as much as 6.5 to 9.2 years' worth of genetic gain as compared to a conventional pig breeding program (Gottardo et al. 2019; Visscher et al. 2000).

\section{Considerations for incorporation of records from animals produced using advanced reproductive or molecular biotechnologies into National Cattle Genetic Evaluations}

Currently, an important question is how to best accommodate animals produced using advanced reproductive and/or molecular biotechnology and their progeny into genetic evaluations. In the U.S., the majority of genetic evaluations for beef cattle are carried out by breed associations following the industry-standard Beef Improvement Federation (BIF) guidelines (BIF 2021d; Van Eenennaam 2019). U.S. dairy cattle genetic evaluations were previously performed by the U.S. Department of Agriculture-Agricultural Research Service-Animal Genomics and Improvement Laboratory (USDA-ARSAGIL) and are currently performed by the Council of Dairy Cattle Breeding (CDCB). Additionally, the International Committee for Animal Recording (ICAR), which is an international Non-Governmental Organization (NGO), provides guidelines, standards, and certification for animal identification, animal recording, and animal evaluation.

\section{Records from animals resulting from ART}

For animals resulting from MOET, BIF recommends that all observations, or phenotypic information, for traits that do not have maternal effects be used in genetic evaluations and that observations "for traits that have maternal effects, be used in genetic evaluations as long as the recipient dams' ages (heifer, 1st parity, or multiparity) and approximate breed compositions are available" (BIF 2021b). Additionally, "BIF recommends that embryo stage (1-9) and grade (1-3) and whether frozen, split, sexed, or genotyped be recorded and submitted to breed association or other recording organization" and that, "when sufficient information becomes available, genetic evaluation models for MOET calves include effects of fresh versus frozen and of biopsied (sexed and/or genotyped) or not" (BIF 2021b). However, due to historic 
concerns of large offspring syndrome, BIF does not recommend to use phenotypic observations from animals resulting from IVP in genetic evaluations (BIF 2021b; Thallman and Snider 2021). Although, BIF does recommend that observations on all ET calves (i.e., resulting from MOET or IVP) be recorded and submitted to breed association or other recording organizations, along with the form of technology used and other pertinent details related to producing the ET calves (BIF 2021b), so that this information could eventually be used in analyses that would enable the incorporation of records from IVP produced beef cattle to be included in future genetic evaluations (Thallman and Snider 2021). In contrast, phenotypic observations from animals resulting from both MOET and IVP are included in dairy cattle genetic evaluations. For dairy animals known to be produced by ET (both MOET and IVP), production records (e.g., lactation records) are included in genetic evaluations, but fertility and calving data (e.g., stillbirth records) are excluded from genetic evaluations of those traits because they don't represent "normal" expressions of fertility (personal communication, John B. Cole).

Regarding animals resulting from NT, due to concerns of large offspring syndrome and abnormal clone syndrome, BIF recommends to not use phenotypic observations from these animals in genetic evaluations (BIF 2021b; Thallman and Snider 2021), but also recognizes that "there are instances where genetically identical animals are in the pedigree (i.e. identical twins and clones)." In these cases where genetically identical animals exist in the pedigree, BIF recommends that, "for purposes of routine genetic evaluation, each set of genetically identical individuals is assigned a common identifier, so they have identical expected progeny differences (EPDs)," and recommends that, "they should also be assigned different permanent identification numbers" (BIF 2021c). An EPD, which is the standard term used in the U.S. beef industry, is a predictor of the genetic merit of an animal's progeny and is equal to half of an animal's EBV. Data from clones is handled similarly for dairy genetic evaluations, where each clone receives a unique permanent identification number and an individual evaluation, but the same predicted transmitting ability (PTA) is distributed for all clones from the same donor (personal communication, John B. Cole). A PTA, which is the standard term used in the U.S. dairy industry, is a predictor of the genetic merit of an animal's progeny and is equal to half of an animal's EBV.

ICAR recommends that detailed data should be recorded at all steps of embryo production (e.g., embryo stage, embryo grade, and whether frozen, split, sexed, or genotyped) and this information should be submitted to breed association or other recording organizations. ICAR is working to develop standardized codes for identifying features of embryos (e.g., sex, NT, IVP, etc.). Additionally, ICAR advises having parentage verification for animals resulting from ET (ICAR, 2017, 2019).

\section{Records from animals resulting from GnEd}

Given that all GnEd animals are currently produced via SCNT or IVP the phenotypic observations of the resulting animals would be recommended to be excluded from beef genetic evaluations, but could potentially be included in dairy genetic evaluations (BIF 2021b; Thallman and Snider 2021). ICAR recommends that "breed Associations should check the rules of their countries with regard to allowing GnEd animals in the herd book," and "if an animal has been GnEd it should be recorded against the animal when registered and should appear on the Zootechnical Certificate" (ICAR 2019). Additionally, BIF has developed more detailed guidelines for what data should be required from GnEd animals for breed association registration (BIF 2021a). Recently, two major beef breed associations, the American Angus Association (AAA) and the Red Angus Association of America (RAAA) adopted bylaws regarding the registration requirements for GnEd founders (GEF) and descendants (GED) (AAA 2021; RAAA 2021). Moreover, in September of 2021 the RAAA was the first breed association to announce that "they will provide herdbook registry of Red Angus animals carrying GnEd traits for heat tolerance and coat color" (RAAA 2021).

Moving forward, the GED will eventually enter genetic evaluations and the method for inclusion of these phenotypic records may differ depending on the type of trait affected by the GnEd (Thallman and Snider 2021). Most GnEd targeting qualitative traits (e.g., horned/polled or coat color), would have no influence on genetic evaluations. In contrast, GnEd targeting quantitative traits (e.g., muscle yield or disease resistance) could have a major impact on the genetic evaluations of close relatives. Thallman and Snider (2021) state that "gene editing directly violates fundamental assumptions of traditional (non-genomic) genetic evaluation." However, they also point out that fortunately, it will likely be easier to accommodate GnEd in genomic evaluation models (e.g., Single Step), and that research will be needed to determine the best way to include these records in different genomic models (Thallman and Snider 2021).

\section{Records from surrogate sires}

Based on the current proposed methods, surrogate sires will also be produced using IVP to generate the germline knockout host for germline complementation (Fig. 6). Therefore, based on current BIF guidelines, phenotypic observations on surrogate sires would also be excluded 
from beef genetic evaluations (BIF 2021b). However, phenotypes recorded on the somatic host are unrelated to the genetic merit of the donor germline, and therefore should not be included in the genetic merit estimate calculations associated with the donor. It should be noted that GnEd, homozygous NANOS2 knockout females are expected to be fertile, so when crossed with a GnEd, heterozygous NANOS2 knockout, fertile male this mating would be expected to produce $50 \%$ homozygous NANOS2 knockout, infertile male offspring, even in the absence of IVP or other ARTs (Park et al. 2017). Similar to animals resulting from ET, it will be useful to record as much information as possible on all contributing factors to the surrogate sire embryo (i.e., sire and dam of the host embryo, identification and genomic information of the germline donor source, ET recipient identification, and details on the production process). Regarding progeny of the surrogate sires, they should be genotyped to confirm inheritance of the germline donor's DNA. Once paternal inheritance is confirmed, then potentially these progeny could be handled similarly to those of clones (BIF 2021), where all offspring data is attributed to the original germline donor and the progeny would all share a common identifier, but also be assigned unique permanent identification.

\section{Considerations for genetic improvement of cattle in developing countries}

Cattle are raised in more than 200 countries around the world in almost all climatic zones, with the exception of high elevations, and they have been bred for adaptations to heat, cold, humidity, extreme diet, water scarcity, mountainous terrain, dry environments, and for general hardiness. In 2019, the Food and Agriculture Organization of the United Nations (FAO) estimated global cattle numbers at 1.511 billion head (FAOSTAT 2020). Across the globe and between individual producers, there is a wide gap in production efficiency, which results in considerable variation, even up to a 50 -fold difference, of the environmental impact of producing the same product (Herrero et al. 2013; Poore and Nemecek 2018). This production efficiency gap is especially large between developed and developing, or Low-to-Middle-Income Countries (LMIC).

For example, while global beef production is currently split evenly between developed (49\%) and developing (51\%) countries, the environmental impact of production is not (FAO 2021b). Presently, LMIC contribute the majority of global ruminant greenhouse gas emission emissions (75\%) and house $76 \%$ of the global cattle herd (FAO 2021a; Herrero et al. 2013). It's important to note, in the 1990's the African continent became the region of the world with the largest number of cattle and now collectively is home to 361 million cattle. This exceeds the 215 million cattle located in Brazil, the individual country with the largest cattle population (\#3 beef producer), and is more than triple the number of cattle in the U.S. (94.8 million head; \#1 beef producer). Ethiopia alone has 63 million cattle, the most of any African country, followed by Sudan and Chad at 31 million head each. In 2019, the African continent accounted for $24 \%$ of the global cattle population, but only $10 \%$ of the global beef production (FAO 2021a, b).

Considering that $81 \%$ of the additional beef production expected by 2029 is predicted to occur in the developing countries of Argentina, Brazil, China, Pakistan, and SubSaharan Africa, this production efficiency gap is a crucial challenge for global cattle production sustainability. For example, Chang et al. (2021) estimated that improving livestock production efficiencies in the 10 countries with the largest emission reduction potential (i.e., the current production efficiency is low, resulting in a high emission intensity per $\mathrm{kg}$ protein, and a large increase in livestock production is projected), could contribute $60 \%-65 \%$ of the global reduction in livestock emissions by 2050 (compared to a baseline where emissions intensities are held constant in the future). Chang et al. (2021) determined that the 10 countries with the largest emission reduction potential were in Africa (Madagascar, Morocco, Niger, South Africa, Tanzania), Asia (China, India, Iran, Turkey) and South America (Brazil).

It is important to keep in mind that beyond meat and milk, cattle also produce fibers, hides, skins, fertilizer, and fuel, are used for transportation and draft power, serve ecological roles, and particularly in Africa and parts of Asia, they also serve socio-economic (e.g., asset building in the form of stock accumulation) and cultural (e.g., religious worship in India and Lobola, or 'bride price' in parts of Africa) purposes. Therefore, careful consideration of livelihood concerns will be required when implementing production efficiency improvements. Van Eenennaam and Werth (2021) explain, "any proposed strategies for boosting the efficiency of cattle production need to consider these broader concerns, and also the fact that access to technologies may more be limited in some settings, often because of factors such as inaccessibility, unaffordability, lack of relevant knowledge, and/ or of organizational capacity." Although some LMIC, like Brazil, have successfully implemented ART on a large commercial scale, not all genetic improvement tools or strategies have translated as easily to other developing countries.

In LMIC, genetic progress can be frustrated by poor infrastructure and ecological and financial challenges (Mapiye et al. 2018; Nyamushamba et al. 2017). For example, in South Africa, it is difficult to develop genetic 
tools such as EBVs for smallholder farmers due to small herds, incomplete data recording for most traits, a lack of parentage recording, insufficient contemporary groups, and lack of organizational capacity (van Marle-Köster and Visser 2018). In a survey of 62 market-oriented smallholder beef farmers in South Africa, $77 \%$ percent of the farmers reported that they were constrained by catthe breeding challenges including a shortage of breeding bulls (12\%), lack of enclosed breeding pens (46\%), and poor breeding management skills (29\%) (Mapiye et al. 2018). Additionally, a number of non-scientific challenges also face emerging market-orientated cattle farmers including land access and ownership issues, and access to financial support and markets (Khapayi and Celliers 2016; Mapiye et al. 2018). These studies suggest that providing South African smallholder farmers with superior genetic material for genetic improvement of their livestock will require different approaches than have been used to implement traditional genetic evaluation programs (van Marle-Köster and Visser 2018). Communitybased breeding programs have seen the most success, especially when they "are based on the breeding goals of smallholder farmers, there are strong market incentives for improved animal productivity, and strong support services such as extension and veterinary services" (de Haas et al. 2016).

The Consultative Group on International Agricultural Research (CGIAR) implemented a collaborative research program to observe, survey, and compare the dairy value chains in Tanzania and Kenya (East Africa), India (South Asia) and Nicaragua (Latin America) (Ojango et al. 2016). In these countries a large number of smallholder farmers that operate mixed crop-livestock production systems play a significant role in dairy production. CGIAR chose to include countries in multiple regions in order to allow for comparisons and cross-system learning that would support development of lessons, methodologies, and technologies of wide applicability (ILRI et al. 2011). This analysis revealed significant productivity gaps especially between large and small-scale producers and identified genetic and reproductive biotechnologies that hold promise for the advancement of global development goals in countries (ILRI et al. 2011).

Among these four countries, Ojango et al. (2016) observed that Kenya was the only country that had a national animal recording system where pedigree and performance recording is conducted. Although open to all producers, the system is primarily used by the largescale dairy producers in high-input systems where purebred cattle are common. At the time, only $2.5 \%$ of the national dairy herd was accounted for in the national animal recording program. This low participation rate is a major obstacle because, as discussed previously, the foundation of genetic improvement is a well-structured breeding program with a clear breeding objective.

Crossbreeding is a more common practice within the smaller-scale livestock production enterprises in both Kenya and Tanzania, where the majority of the smallholder farmers have less than five cows. However, indiscriminate or uncontrolled crossbreeding can lead to the demise of indigenous breeds (van Marle-Köster and Visser 2018). For instance, unstructured crossbreeding programs in Africa have produced non-descript crossbred cattle that now constitute more than two thirds of the smallholder herd (Scholtz et al. 2008). It has been suggested that, structured breeding programs of African indigenous livestock should be developed (Mwai et al. 2015), informed by knowledge of the population structure and genetic diversity of these breeds (Nyamushamba et al. 2017). Such developments should include active farmer participation in the selection of superior indigenous sires based on the local breeding objectives using a community based breeding program model (Mapiye et al. 2019).

The CGIAR study found that AI was the most widely used reproductive biotechnology in all four countries, especially in large-scale dairy systems. However, it has proven more difficult to successfully implement in smallholder cattle production systems in developing countries due to logistical and institutional challenges (Ojango et al., 2016).

In other LMIC, crossbreeding via AI has been used to try to intensify the beef cattle sector with limited success. For example, in Indonesia in the 1980s, the government promoted the AI of the local Ongole cattle with Simmental and Limousin semen to produce more productive F1 animals. In this country with a population of 270 million people and 17 million cattle, $90 \%$ of cattle production is from smallholder farming systems with about 6.5 million farmers living in the rural areas. These crossbred animals were not supported with better feed and health services, which limited their potential and the cattle keeping systems did not become more efficient through crossbreeding (Agus and Mastuti Widi 2018). More recently, a program which translated into "a cow must be pregnant" was launched in 2016 and set a target of 4 million head of productive cows inseminated to produce 3 million calves, this time with the support of improved feed provided by planting improved pastures and legumes, and the provision of health services. A report on the success of this program details some of the problems encountered in getting frozen semen to remote locations, difficulty in getting cattle in the right body condition score to be reproductively cycling, and lack of farming experience (Setiawan 2018). Additionally, in a survey conducted in another region of Indonesia, adoption of AI was found 
to be inversely correlated with farmer age and cost of AI (Setiana et al. 2020).

In recent years, genomics has started to be used to try to identify animals that have both enhanced productivity and adaptation to African conditions (Marshall et al. 2019; van Marle-Köster and Visser 2018). Crossbred animals that retain some of the resilience of indigenous breeds while being more productive can improve production efficiency. In a case study with dairy production in Senegal, crossbred indigenous zebu by Bos taurus dairy cattle, as identified by genomics, and kept under better management produced up to 7.5 -fold higher milk-yields, eightfold higher household profit, and threefold lower greenhouse gas emission intensity, per cow per annum, in comparison to indigenous Zebu kept under poorer management, for a typical herd size of eight animals (Salmon et al. 2018). There are glaring disparities when it comes to the implementation of GS in LMICs, and even among small breeds in the developed world. GS is not a scaleneutral technology, advantaging large breeds and genetic providers over small ones. It is difficult to implement in the absence of structured breeding programs with sufficiently sized genotyped and phenotyped reference populations. Therefore, more investment in data recording and structured breeding programs, linked to multiplication and delivery systems that can be delivered at scale will be needed to enable genetics and genomic technologies to deliver sustained benefits in LMIC cattle production systems.

Additionally, genomics can provide information on important traits of indigenous breeds. For example, it is well known that African cattle have improved thermotolerance levels and an increased ability to regulate their body temperature (Kim et al. 2017a). It has been suggested that the greatest benefit of genomics to smallholder farmers might be the characterization of the drought tolerant, resistance to ticks and tick-borne diseases, thermo tolerance and resistance to trypanosomosis traits present in adapted native breeds (Kim et al. 2017b; Nyamushamba et al. 2017). Other potential genotype-derived information includes the breed composition of the animal, which may be particularly useful in devising structured crossbreeding strategies (Kuehn et al. 2011; Marshall et al. 2019; Ojango et al. 2014).

GnEd could potentially be a useful tool for genetic improvement of cattle in LMIC because GnEd can be used to efficiently introduce useful Mendelian traits from other breeds into existing, locally adapted breeds, rather than having to introgress useful alleles via crossbreeding. Additionally, GnEd could be used to introduce novel beneficial traits (e.g., disease resistance), possibly from different species. In Africa, a particular focus has been placed on using GnEd to combat animal disease (Karavolias et al. 2021). One approach is to gene edit virulence genes of parasites, like Theileria parva, to weaken the pathogen so that it could be used in the development of a more effective vaccine against East Coast Fever, which is a disease that is estimated to kill one cow every $30 \mathrm{~s}$ across a dozen African countries (Enahoro et al. 2019; Karembu 2021). Alternatively, GnEd could be used to introduce disease resistance into indigenous breeds of cattle. For example, the Apolipoprotein L1 (ApoL 1) gene has been found to confer resistance to trypanosomiasis in primates (O'Toole et al. 2017), and African researchers are currently working to use the CRISPR/Cas9 system to knock-in Apol 1 into an indigenous goat breed (Karembu 2021). If successful, this GnEd scheme could also be used to combat the devastating disease of trypanosomiasis in cattle.

It is important to keep in mind that the effective and efficient use of GnEd will require infrastructure to perform ART to both facilitate the production of animals, and the dissemination of improved traits. To accelerate rates of genetic gain, a structured breeding program, ideally including GS, should be used to ensure that the best (i.e., highest genetic merit) parents of and/or animals are put forward as selection candidates. This alone would improve production and accelerate genetic improvement, even in the absence of GnEd. Additionally, surrogate sires distributing elite, locally adapted genetics, with or without useful GnEd traits, could provide a workable approach for the more widespread dissemination of improved genetics via natural service.

\section{Regulatory considerations for tools for the genetic improvement of cattle Regulation of GS}

Animals produced from conventional breeding methods are routinely evaluated for changes in productivity, reproductive efficiency, reactions to disease, and quality characteristics by breeders. However, they are not subject to regulatory approval, other than it is illegal to sell unsafe food irrespective of the breeding method that was used to produce it. Regulatory agencies do not evaluate new conventionally bred varieties or breeds for health and environmental safety or approve their sale prior to commercial release; nor are they evaluated for unintended effects at the molecular level. There are more than 86.5 million known genetic variants between different breeds of cattle, including 2.5 million insertions and deletions of one, or more, base pairs of DNA, and 84 million single nucleotide variants (Hayes and Daetwyler 2019). Genetic variation per se does not pose a unique hazard as it relates to food safety (Van Eenennaam et al. 2019). The variations fuel genetic improvement programs and drive GS, which was rapidly adopted in livestock breeding 


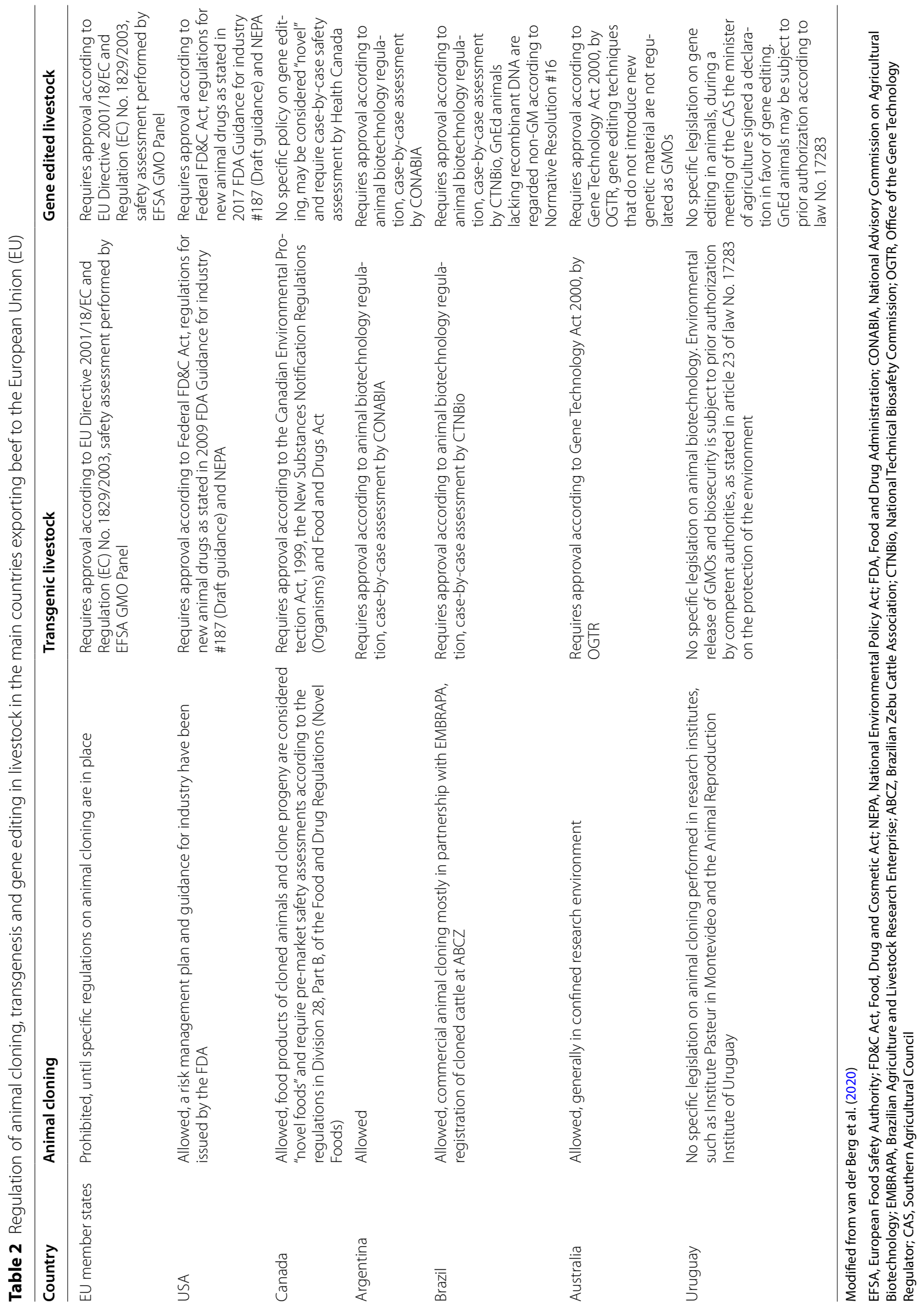


programs globally, in the absence of any specific regulatory oversight or approvals or public controversy.

\section{Regulation of cloning}

In North America, South America, and New Zealand, cloning for agricultural purposes is not legally restricted (Table 2). Additionally, both the U.S. Food and Drug Administration (FDA) in 2008, and the European Food Safety Authority (EFSA) in 2012, concluded that products derived from animal clones are not different from those derived from non-cloned animals. However, in the European Union (EU), food derived from animal clones falls under the 'Novel Foods Regulation,' as food derived from animals obtained by non-traditional breeding practices. Current regulation in the EU has placed a ban on food products from animal clones due to, amongst others, ethical considerations regarding animal welfare. This ban does not cover products from their progeny, which are considered to be indistinguishable from traditionally bred livestock (van der Berg et al. 2019). Currently, no company in Europe is contemplating bringing products derived from animal clones, or their offspring, to market (Galli and Lazzari 2021). In contrast, several companies in other parts of the world now specialize in cloning farm animals (van der Berg et al. 2019). A Supply Chain Management Program to identify cloned livestock in the U.S. was set up by Viagen and Trans Ova in 2007. However, according to these companies, although the program was run from 2008 until 2012, no other cloning companies showed interest in participating in the program, and it was never accessed by industry (van der Berg et al. 2019).

\section{Regulation of genetic engineering (Transgenesis)}

Genetically engineered (GE) or transgenic cattle have been around since the 1990s, but none have ever been successfully commercialized for food or feed production. In 2008, the Codex Alimentarius Commission published guidelines for the safety assessment of foods derived from recombinant DNA (rDNA) animals (FAO/WHO 2008). A "rDNA Animal" is defined as "an animal in which the genetic material has been changed through in vitro nucleic acid techniques, including rDNA and direct injection of nucleic acid into cells or organelles." The guidelines recommend evaluations of product composition and animal health as essential steps in ensuring the safety of food derived from rDNA animals. Only a single GE food animal application has ever been sold for food consumption, the fast-growing AquAdvantage salmon, and even then, only in Canada and the U.S. The regulatory approval process for this product took over 20 years and several million dollars (Van Eenennaam et al. 2021). A second GE food animal application approval, for an Alpha-gal (galactose- $\alpha$-1,3-galactose) knockout "GalSafe" pig, was announced by the FDA in 2020, for a line of pigs that was first reported in the literature in 2003 (Phelps et al. 2003). This pig was developed using a traditional gene knockout approach and carries a plasmid (pPL657) rDNA construct disrupting the Alpha-gal gene along with the neomycin phosphotransferase (nptII) selection marker gene in its genome. The approval was for a single swine farm to produce a maximum of 1000 GalSafe $^{\circledR}$ pigs annually to be raised in the absence of aminoglycosides, such as neomycin, to produce meat that is safe for consumption for people with Alpha-gal syndrome and porcine-based materials to produce human medical products.

\section{Regulation of GnEd}

The regulatory picture for GnEd is currently mixed (Table 2). Argentina was the first country to publish their proposed approach to the regulation of GnEd organisms. The trigger for regulation is whether animals carry a "novel combination of genetic material" (i.e., transgenic). Those that do will be considered a "GMO" (Genetically Modified Organism) under Argentine law, and those that do not will not trigger additional regulatory oversight (Whelan and Lema 2015). The Argentine regulation calls for GnEd plants and animals to be presented to the biosafety commission in order to establish, on a case by case basis, whether it is a GMO. An interesting aspect of this regulation is that there is an opportunity to present projects at the "design stage," whereby a preliminary opinion based on the expected outcome of the project will be issued by the commission. Later, when the plants or animals have been obtained and fully characterized, applicants must present a follow up report that will be used to establish a final decision. That determination is mostly based on any changes present in the genome of the product intended to be sold commercially.

Conversely, in the EU, New Zealand, and the U.S., $\mathrm{GnEd}$ is being treated as equivalent to $\mathrm{GE}$, with implications for global trade.

The Department of Biotechnology in India published draft guidelines for GnEd regulation in 2020. These guidelines propose a tiered approach depending upon the characteristics of the end product, but include requirements for a quite extensive characterization of trait efficacy and phenotypic equivalence of GnEd organisms triggered solely by the use of GnEd, and which is not required for those plants and animals resulting from conventional breeding.

To date, no African nation has passed regulations for GnEd animals, but similar to India, proposed guidelines are being drafted in many countries. Kenya has begun drafting guidelines to regulate GnEd products, using the Argentinean approach as a model. The draft guidelines 
define what needs to be regulated, what is partially regulated and what is not regulated at all. Kenya's National Biosafety Authority (NBA) has approved, at the research level, six applications for genome editing applications in agriculture, including one application focused on making pigs resistant to African swine fever. Other applications include improving banana and yam to resist two destructive plant viruses.

The decision by the FDA to regulate GnEd animals-or more correctly the intentional alterations in the genome of animals-as new animal drugs irrespective of product risk was done in the absence of public discourse. Similarly, the decision by the European Court of Justice that genome edited organisms would be subject to the full range of testing and regulation as if they were transgenic according to the EU Directive, was made without engagement with the public. Moreover, the decision by the European Court of Justice effectively side-stepped any processes of wider societal discussion (Bruce and Bruce 2019). In considering this decision, these authors wrote, "regulation sets bounds to what can be done, who can do it and under what conditions can things be done. But if there has been no discussion with the public, this could be argued to be a case where regulation has been socially premature, and not done on behalf of the society."

Interestingly, following the United Kingdom's (UK) departure from the EU, a public consultation was held in 2021 by the UK government's Department for Environment, Food and Rural Affairs (DEFRA) as to whether GnEd technology should be regulated in the same way as GE, if it yields a result that could have been produced by conventional breeding. Following this consultation, it was determined that UK plant researchers who planned to conduct field trials of GnEd plants no longer need to submit risk assessments to DEFRA, but UK research involving GnEd animals will continue to be regulated as before to ensure animal-welfare standards are met (Ledford 2021).

While a highly precautionary regulatory approach may be of little consequence in food-secure developed regions like North America and the EU, such an approach is likely to hinder the adoption of GnEd in some LMIC that could most benefit from targeted applications, such as diseaseresistant livestock. For resource-poor Africa, responding to the promises and challenges of GnEd is likely to be complex, not least because most lack the capacity for regulatory oversight. Additionally, if GnEd livestock are not required to undergo unique regulatory approval in some parts of the world, they will not necessarily be segregated from conventionally bred animals and there will often be no way to uniquely detect the products derived from them, especially if the genetic alteration already exists in the target population. This is somewhat analogous to the situation for clones, where there is no molecular way to differentiate or track the products from a clone as compared to those of its progenitor.

\section{Public perception of GnEd}

In countries where food security is not a priority, consumer acceptance of GnEd animals is expected to be lower, especially for those applications offering economic advantages mainly to the livestock producer. Bruce and Bruce (2019) considered two examples of GnEd in livestock; hornless cattle and disease resistant pigs, from the perspective of Responsible Research and Innovation (RRI). They suggested that the public's knowledge gap of current practices in livestock agriculture, could lead to unexpected outcomes from public consultations. For example, if an argument is made regarding using GnEd to introduce the POLLED allele, the advantage of polled cattle might not be immediately obvious to those not versed in agricultural practice, and more generally "the need for dehorning may be considered shocking by some publics" (Bruce and Bruce 2019).

A 2017 public consultation performed by the UK Royal Society found that GnEd animal applications that targeted reducing antibiotic use, greenhouse gas emissions, and zoonotic disease transmission were all deemed acceptable (van Mil et al. 2017). However, it should be noted that a major pre-occupation of these participants in this consultation was to ensure GnEd was used to address inequality. The participants were particularly concerned about who owns the technology, who gets rich from its use, and whether it could be used to unfairly obtain monopoly power (van Mil et al. 2017). This raises interesting questions regarding whether the GnEd regulatory approaches that have been proposed in the U.S. and EU are fit for purpose (Van Eenennaam et al. 2019), as they advantage large companies and incentivize intellectual property protection. The latter of which may prove to be disruptive to the cattle breeding industry (Bruce 2017).

Evidence from Mora et al. (2012) suggested that if geographic differences are considered, consumers' acceptance of GE animals would be higher in developing countries where the requirement for enhanced food production might be met by application of this technology (Van Eenennaam and Young 2018). Historically, the debates around GE crops in Africa have been dominated by a few elite scientists or largely international NGOs, leading to a polarization that bypassed the farmers most directly affected by decisions. Roughly $65 \%$ of Africa's population relies on smallholder farming, and these farms are not highly productive. To date, only eight African countries have commercialized GE crops; Burkina Faso, Eswatini, Ethiopia, Kenya, Malawi, Nigeria, Sudan 
and South Africa, mostly insect-resistant Bt cotton and recently Bt cowpea in Kenya. Kenya, Nigeria and Eswatini are leading the agricultural GnEd research as they see its potential to increase farmers' income in Africa. As of yet, there is little research specifically gauging the acceptability of the use of GnEd livestock in LMIC, especially among the smallholder farmers and livestock keepers who would be most affected by any decisions around the technology.

\section{Conclusions}

Genetic improvement of livestock around the globe has been, and will continue to be, an important driver of the sustainability of animal agriculture. Livestock genetic improvement programs, beginning with selective breeding using statistical prediction methods (e.g., EBVs) and more recently GS, in combination with ART have enabled more accurate selection and intense utilization of genetically superior parents for the next generation to accelerate rates of genetic gain. Most recently, the ability to use GnEd to inactivate targeted gene function (i.e., knockout genes), knock-in genes, or achieve allele introgression in the absence of undesired linkage drag, offers promising opportunities to introduce useful genetic variation into livestock breeding programs. GnEd experiments in cattle have primarily focused on three main areas of improvement (1) animal health and welfare, (2) product yield or quality, and (3) reproduction or novel breeding schemes, which are all areas that are highly aligned with the goals of conventional breeding programs. Presently, GnEd is well-suited for introgressing alleles affecting typically qualitative, Mendelian traits at a more rapid pace than is possible using conventional selection alone. However, most of the traits that animal breeders seek to improve are polygenic and quantitative. Additionally, GnEd in livestock is only possible through the use of ART. Therefore, in order for GnEd to be an effective tool for genetic change it will need to seamlessly integrate into a structured breeding program with a clear breeding objective and ideally be used in conjunction with ART and GS to accelerate genetic gain by simultaneously altering multiple components of the breeder's equation. To accomplish this, several GnEd schemes have been modeled for livestock populations. The most efficient schemes have relied heavily on widespread adoption of ART, especially commercial sector use of AI. Considering the currently limited adoption of AI around the world and specifically in the commercial beef industry, novel breeding schemes, such as $\mathrm{GnEd}$ applied to surrogate sire production, will likely be required to widely disseminate desired traits improved via GnEd. The lack of global regulatory harmonization around GnEd animals and products from these animals, including semen and embryos, will pose challenges in relation to global trade, and aspects of traceability in both animal breeding and the food chain.

\section{Abbreviations}

AAA: American Angus Association; ABCZ: Brazilian Zebu Cattle Association; Al: Artificial insemination; Apol 1: Apolipoprotein L1; ART: Assisted reproductive technologies; BIF: Beef Improvement Federation; BLG: Beta-lactoglobulin; BRD: Bovine respiratory disease; BSE: Bovine spongiform encephalopathy; CAS: Southern Agricultural Council; CDCB: Council of Dairy Cattle Breeding; CGIAR: Consultative Group on International Agricultural Research; CONABIA: National Advisory Commission on Agricultural Biotechnology; CPI: Cytoplasmic injection; CRISPR/Cas9: Clustered regularly interspersed short palindromic repeats and associated protein 9; CSN2: Beta-casein; CTNBio: National Technical Biosafety Commission; DAZL: Deleted in AZoospermia Like; DEFRA: Department for Environment, Food and Rural Affairs; DSB: Double stranded breaks; FAO: Food and Agriculture Organization of the United Nations; FDA: Food and Drug Administration; FD\&C Act: Food, Drug and Cosmetic Act; EBV: Estimated breeding value; ECNT: Embryonic cell nuclear transfer; EFSA: European Food Safety Authority; EMBRAPA: Brazilian Agriculture and Livestock Research Enterprise; EP: Electroporation; EPSC: Expanded potential stem cells; EPD: Expected progeny difference; ESC: Embryonic stem cells; ET: Embryo transfer; EU: European Union; JIVET: Juvenile in vitro ET; GE: Genetically engineered; GEBV: Genomic estimated breeding values; GED: Gene edited descendants; GEF: Gene edited founders; GMO: Genetically Modified Organism; GnEd: Gene editing; GS: Genomic selection; GSE: Genomic screening of embryos; HDR: Homology-directed repair; IARS: Isoleucyl-tRNA synthetase; ICAR: International Committee for Animal Recording; ICBF: Irish Cattle Breeding Federation; ICM: Inner cell mass; ILRI: International Livestock Research Institute; iPSC: Induced pluripotent stem cells; ITGB2: Integrin subunit beta 2; IVB: In vitro Breeding; IVP: In vitro Embryo production; IVC: In vitro Culture; IVF: In vitro Fertilization; IVM: In vitro Maturation; LacS: Sulfolobus solfataricus beta-glycosidase; LMIC: Low-to-Middle-Income Countries; MLA: Meat and Livestock Australia; MOET: Multiple ovulation embryo transfer; MSTN: Myostatin; NANOS2: Nanos C2HCType Zinc Finger 2; NASEM: National Academies of Sciences, Engineering, and Medicine; NEPA: National Environmental Policy Act; NGO: Non-Governmental Organization; NHEJ: Non-homologous end joining; NM\$: Lifetime Net Merit selection index; NT: Nuclear transfer; OGTR: Office of the Gene Technology Regulator; OPU: Ovum-pick up; PAGE: Promotion of alleles by gene editing; $P_{C}$ : POLLED, Celtic allele; PCR: Polymerase chain reaction; PGCLC: Primordial germ cell-like cells; PMEL: Premelanosomal protein gene; PRLR: Prolactin receptor; PRNP: Prion protein; PTA: Predicted transmitting ability; QTN: Quantitative trait nucleotides; RAAA: Red Angus Association of America; rDNA: Recombinant DNA; SNP: Single nucleotide polymorphisms; SCNT: Somatic cell nuclear transfer; SRY: Sex determining region Y protein; SSC: Spermatogonial stem cells; TAI: Timed artificial insemination; TET: Timed embryo transfer; TALEN: Transcription activator-like effector nucleases; UK: United Kingdom; U.S.: United States; USDA: United States Department of Agriculture; USDA-ARS-AGIL: United States Department of Agriculture-Agricultural Research Service-Animal Genomics and Improvement Laboratory; WHO: World Health Organization; ZFN: Zinc finger nucleases.

\section{Acknowledgements}

Not applicable.

\section{Authors' contributions}

MM performed the literature review and wrote the first draft of the manuscript, with input from AVE. Both authors read and approved the final manuscript.

\section{Authors' information}

MM is an Animal Biology Ph.D. candidate working in the laboratory of AVE. AVE is a Professor of Cooperative Extension in Animal Biotechnology and Genomics in the Department of Animal Science at the University of California, Davis.

\section{Funding}

This work was supported by the National Institute for Food and Agriculture (NIFA), National Needs Graduate and Postgraduate Fellowship (No. 201738420-26790) and Predoctoral Fellowship (No. 2021-67034-35150) from the U.S. Department of Agriculture (USDA). 
Availability of data and materials

Not applicable.

\section{Declarations}

Ethics approval and consent to participate

Not applicable.

\section{Consent for publication}

Not applicable.

\section{Competing interests}

The authors declare that they have no competing interests.

Received: 27 November 2021 Accepted: 27 January 2022 Published online: 04 March 2022

\section{References}

American Angus Association (AAA). Breeder's Reference Guide - Part 2: Association Rules, 104-f. St. Joseph, MO; 2021. https://www.angus.org/pub/ brg_part2.pdf. Accessed 10 Oct 2021.

Agus A, Mastuti Widi TS. Current situation and future prospects for beef cattle production in Indonesia - A review. Asian-Australas J Anim Sci. 2018;31(7):976-83. https://doi.org/10.5713/ajas.18.0233.

Akagi S, Geshi M, Nagai T. Recent progress in bovine somatic cell nuclear transfer. Anim Sci J. 2013;84(3):191-9. https://doi.org/10.1111/asj.12035.

Allan MF. Past, Present and Future of Genetic Embryo Testing in Cattle. Beef Improvement Federation (BIF) Research Symposium and Convention; Brookings, SD, June 18-21, 2019.

Banks R. Challenges with investing in genetic improvement for the Australian extensive livestock industries. Aust J Exp Agric. 2005;45(8):1033-9.

Baruselli PS, Catussi BLC, Abreu LÂ, Elliff FM, Silva LG, Batista EOS. Challenges to increase the Al and ET markets in Brazil. Anim Reprod. 2019;16:364-75.

Baruselli PS, Ferreira RM, Sá Filho MF, Bó GA. Review: Using artificial insemination v natural service in beef herds. Animal. 2018;12(1):s45-52. https:// doi.org/10.1017/S175173111800054X.

Barwick SA, Henzell AL, Herd RM, Walmsley BJ, Arthur PF. Methods and consequences of including reduction in greenhouse gas emission in beef cattle multiple-trait selection. Genet Sel Evol. 2019;51(1):18. https://doi. org/10.1186/s12711-019-0459-5.

Bastiaansen JWM, Bovenhuis H, Groenen MAM, Megens H-J, Mulder HA. The impact of genome editing on the introduction of monogenic traits in livestock. Genet Sel Evol. 2018;50(1):18. https://doi.org/10.1186/ s12711-018-0389-7.

Berry DP, Garcia JF, Garrick DJ. Development and implementation of genomic predictions in beef cattle. Anim Front. 2016;6(1):32-8. https://doi.org/ 10.2527/af.2016-0005.

Bertolini M, Bertolini L. Advances in reproductive technologies in cattle: from artificial insemination to cloning. Revis Fac Med Vet Zootecnia. 2009;56(3):184-94.

Bevacqua RJ, Fernandez-Martín R, Savy V, Canel NG, Gismondi MI, Kues WA, et al. Efficient edition of the bovine PRNP prion gene in somatic cells and IVF embryos using the CRISPR/Cas9 system. Theriogenology. 2016;86(8):1886-96.e1. https://doi.org/10.1016/j.theriogenology.2016. 06.010 .

BIF $^{\mathrm{a}}$. Data From Gene Edited Animals. Beef Improvement Federation (BIF) Guidelines Wiki; 2021a. http://guidelines.beefimprovement.org/index. php?title=Data_From_Gene_Edited_Animals\&oldid=2474. Accessed 15 Oct 2021.

BIF $^{\text {b }}$. Embryo Transfer (ET): Data Collection And Utilization. Beef Improvement Federation (BIF) Guidelines Wiki; 2021b. http://guidelines.beefimprov ement.org/index.php/Embryo_Transfer_(ET):_Data_Collection_And_ Utilization. Accessed 15 Oct 2021.

$\mathrm{BIF}^{\mathrm{C}}$. Expected Progeny Difference. Beef Improvement Federation (BIF) Guidelines Wiki; 2021c. http://guidelines.beefimprovement.org/index.php/ Expected_Progeny_Difference. Accessed 15 Oct 2021.

BIF $^{\mathrm{d}}$. Guidelines for Uniform Beef Improvement Programs. Beef Improvement Federation (BIF) Guidelines Wiki; 2021d. http://guidelines.beefimprov
ement.org/index.php/Guidelines_for_Uniform_Beef_Improvement_ Programs. Accessed 15 Oct 2021.

Bishop TF, Van Eenennaam AL. Genome editing approaches to augment livestock breeding programs. J Exp Biol. 2020;223(1): 207159. https:// doi.org/10.1242/jeb.207159.

Blomberg LA, Telugu B. Twenty years of embryonic stem cell research in farm animals. Reprod Domest Anim. 2012;47:80-5. https://doi.org/10.1111/j. 1439-0531.2012.02059.x.

Bogliotti YS, Wu J, Vilarino M, Okamura D, Soto DA, Zhong C, et al. Efficient derivation of stable primed pluripotent embryonic stem cells from bovine blastocysts. Proc Natl Acad Sci. 2018;115(9):2090-5. https://doi. org/10.1073/pnas.1716161115.

Bondioli KR. Embryo sexing: a review of current techniques and their potential for commercial amdication in livestock production. J Anim Sci. 1992;70(2):19-29. https://doi.org/10.2527/1992.70suppl_219x.

Bousquet D, Blondin P. Review: potential uses of cloning in breeding schemes: dairy cattle. Cloning Stem Cells. 2004;6(2):190-7. https://doi.org/10. 1089/1536230041372373.

Brogliatti GM, Adams GP. Ultrasound-guided transvaginal oocyte collection in prepubertal calves. Theriogenology. 1996;45(6):1163-76. https://doi. org/10.1016/0093-691X(96)00072-6.

Bruce A. Genome edited animals: Learning from GM crops? Transgenic Res. 2017;26(3):385-98. https://doi.org/10.1007/s11248-017-0017-2.

Bruce A, Bruce D. Genome editing and responsible innovation, can they be reconciled? J Agric Environ Ethics. 2019;32(5):769-88. https://doi.org/ 10.1007/s10806-019-09789-w.

Burrow HM. The effects of inbreeding on productive and adaptive traits and temperament of tropical beef cattle. Livest Prod Sci. 1998;55(3):227-43. https:// doi.org/10.1016/S0301-6226(98)00139-0.

Capper JL, Cady RA. The effects of improved performance in the US dairy cattle industry on environmental impacts between 2007 and 2017. J Anim Sci. 2019;98:1. https://doi.org/10.1093/jas/skz291.

Capper JL, Cady RA, Bauman DE. The environmental impact of dairy production: 1944 compared with 2007. J Anim Sci. 2009;87(6):2160-7. https://doi.org/10. 2527/jas.2009-1781.

Carlson DF, Lancto CA, Zang B, Kim E-S, Walton M, Oldeschulte D, et al. Production of hornless dairy cattle from genome-edited cell lines. Nat Biotechnol. 2016;34(5):479-81. https://doi.org/10.1038/nbt.3560.

Carlson DF, Tan W, Lillico SG, Stverakova D, Proudfoot C, Christian M, et al. Efficient TALEN-mediated gene knockout in livestock. Proc Natl Acad Sci. 2012;109(43):17382-7. https://doi.org/10.1073/pnas.1211446109.

Cenariu M, Pall E, Cernea C, Groza I. Evaluation of bovine embryo biopsy techniques according to their ability to preserve embryo viability. J Biomed Biotechnol. 2012;2012: 541384. https://doi.org/10.1155/2012/541384.

Chang J, Peng S, Yin Y, Ciais P, Havlik P, Herrero M. The key role of production efficiency changes in livestock methane emission mitigation. AGU Advances. 2021;2(2): e2021000391. https://doi.org/10.1029/2021AV000391.

Chohan KR, Hunter AG. In vitro maturation, fertilization and early cleavage rates of bovine fetal oocytes. Theriogenology. 2004;61(2-3):373-80. https://doi.org/ 10.1016/S0093-691X(03)00220-6.

Choi W, Kim E, Yum S-Y, Lee C, Lee J, Moon J, et al. Efficient PRNP deletion in bovine genome using gene-editing technologies in bovine cells. Prion. 2015:9(4):278-91. https://doi.org/10.1080/19336896.2015.1071459.

Ciccarelli M, Giassetti MI, Miao D, Oatley MJ, Robbins C, Lopez-Biladeau B, et al. Donor-derived spermatogenesis following stem cell transplantation in sterile NANOS2 knockout males. Proc Natl Acad Sci. 2020;117(39):24195-204. https://doi.org/10.1073/pnas.2010102117.

de Haas Y, Davis S, Reisinger A, Richards MB, Difford G, Lassen J. Pracice Brief: Improved ruminant genetics: Implementation guidance for policymakers and investors. Global Alliance of Climate-Smart Agriculture; 2016. https://globalresearchalliance.org/wp-content/uploads/2018/02/CSAPractice-Brief_Animal-Breeding-Sept-2016.pdf.

de Sousa RV, da Silva Cardoso CR, Butzke G, Dode MAN, Rumpf R, Franco MM. Biopsy of bovine embryos produced in vivo and in vitro does not affect pregnancy rates. Theriogenology. 2017;90:25-31. https://doi.org/10. 1016/j.theriogenology.2016.11.003.

Duby RT, Damiani P, Looney CR, Fissore RA, Robl JM. Prepuberal calves as oocyte donors: Promises and problems. Theriogenology. 1996;45(1):121-30. https://doi.org/10.1016/0093-691X(95)00361-B. 
Enahoro D, Herrero M, Johnson N. Promising options for improving livestock production and productivity in developing countries. Nairobi, Kenya: ILRI: ILRI Project Report; 2019. https://hdl.handle.net/10568/105759.

Evans MJ, Kaufman MH. Establishment in culture of pluripotential cells from mouse embryos. Nature. 1981;292(5819):154-6. https://doi.org/10. 1038/292154a0.

Ezashi T, Yuan Y, Roberts RM. Pluripotent stem cells from domesticated mammals. Annu Rev Anim Biosci. 2016;4:223-53.

Food and Agriculture Organization of the United Nations ${ }^{a}$. FAOSTAT Statistical Database-Production-Live Animals. Rome, Italy; 2021a. http://www.fao. org/faostat/en/?\#data/QA. Accessed 10 Mar 2021.

Food and Agriculture Organization of the United Nations ${ }^{b}$. FAOSTAT Statistical Database-Production-Live Primary. Rome, Italy; 2021b. http:// www.fao.org/faostat/en/?\#data/QL. Accessed 10 Mar 2021.

Food and Agriculture Organization of the United Nations/World Health Organization. Guideline for the Conduct of Food Safety Assessment of Foods Derived From Recombinant-DNA Animals CAC/CL 68-2008. Rome, Italy; 2008. https://www.who.int/docs/default-source/foodsafety/food-genetically-modified/cxg-068e.pdf?sfvrsn=c9de948e_2. Accessed 30 Oct 2021

Fennessy P, Byrne T, Proctor L, Amer P. The potential impact of breeding strategies to reduce methane output from beef cattle. Anim Prod Sci. 2019;59(9):1598-610.

Figueiredo JR, Hulshof SCJ, Van den Hurk R, Ectors FJ, Fontes RS, Nusgens B, et al. Development of a combined new mechanical and enzymatic method for the isolation of intact preantral follicles from fetal, calf and adult bovine ovaries. Theriogenology. 1993;40(4):789-99. https:// doi.org/10.1016/0093-691X(93)90214-P.

Fisher P, DL H, et al. Potential for genomic selection of bovine embryos. In: Proceedings of the New Zealand Society of Animal Production; Christchurch: New Zealand Society of Animal Production.

Gaj T, Gersbach CA, Barbas CF. ZFN, TALEN and CRISPR/Cas-based methods for genome engineering. Trends Biotechnol. 2013;31(7):397-405. https://doi.org/10.1016/j.tibtech.2013.04.004.

Galli C, Lazzari G. 25th ANNIVERSARY OF CLONING BY SOMATIC-CELL NUCLEAR TRANSFER: Current applications of SCNT in advanced breeding and genome editing in livestock. Reproduction. 2021;162(1):F23-32. https://doi.org/10.1530/rep-21-0006.

Gao Y, Wu H, Wang Y, Liu X, Chen L, Li Q, et al. Single Cas9 nickase induced generation of NRAMP1 knockin cattle with reduced off-target effects. Genome Biol. 2017;18(1):13. https://doi.org/10.1186/ s13059-016-1144-4.

García-Ruiz A, Cole JB, VanRaden PM, Wiggans GR, Ruiz-López FJ, Van Tassell CP. Changes in genetic selection differentials and generation intervals in US Holstein dairy cattle as a result of genomic selection. Proc Natl Acad Sci. 2016;113(28):E3995-4004. https://doi.org/10.1073/ pnas.1519061113.

Gaspa G, Veerkamp RF, Calus MPL, Windig JJ. Assessment of genomic selection for introgression of polledness into Holstein Friesian cattle by simulation. Livest Sci. 2015;179:86-95. https://doi.org/10.1016/j.livsci. 2015.05.020.

Georges M, Charlier C, Hayes B. Harnessing genomic information for livestock improvement. Nat Rev Genet. 2019;20(3):135-56. https://doi. org/10.1038/s41576-018-0082-2.

Georges M, Massey JM. Velogenetics, or the synergistic use of marker assisted selection and germ-line manipulation. Theriogenology. 1991;35(1):151-9. https://doi.org/10.1016/0093-691X(91)90154-6.

Giassetti MI, Ciccarelli M, Oatley JM. Spermatogonial stem cell transplantation: insights and outlook for domestic animals. Annu Rev Anim Biosci. 2019;7(1):385-401. https://doi.org/10.1146/annur ev-animal-020518-115239.

Goszczynski DE, Cheng H, Demyda-Peyrás S, Medrano JF, Wu J, Ross PJ. In vitro breeding: application of embryonic stem cells to animal production. Biol Reprod. 2018;100(4):885-95. https://doi.org/10. 1093/biolre/ioy256.

Gottardo F, Nalon E, Contiero B, Normando S, Dalvit P, Cozzi G. The dehorning of dairy calves: Practices and opinions of 639 farmers. J Dairy Sci. 2011;94(11):5724-34. https://doi.org/10.3168/jds.2011-4443.

Gottardo P, Gorjanc G, Battagin M, Gaynor RC, Jenko J, Ros-Freixedes R, et al. A strategy to exploit surrogate sire technology in livestock breeding programs. Genes Genome Genet. 2019;9(1):203-15. https://doi.org/ 10.1534/g3.118.200890.

Granleese T, Clark SA, Swan AA, van der Werf JHJ. Increased genetic gains in sheep, beef and dairy breeding programs from using female reproductive technologies combined with optimal contribution selection and genomic breeding values. Genet Sel Evol. 2015;47(1):70. https:// doi.org/10.1186/s12711-015-0151-3.

Hayashi K, Ogushi S, Kurimoto K, Shimamoto S, Ohta H, Saitou M. Offspring from oocytes derived from in vitro primordial germ cell-like cells in mice. Science. 2012;338(6109):971-5. https://doi.org/10.1126/scien ce. 1226889 .

Hayashi K, Ohta H, Kurimoto K, Aramaki S, Saitou M. Reconstitution of the mouse germ cell specification pathway in culture by pluripotent stem cells. Cell. 2011;146(4):519-32. https://doi.org/10.1016/j.cell.2011.06.052.

Hayes BJ, Daetwyler HD. 1000 Bull genomes project to map simple and complex genetic traits in cattle: applications and outcomes. Annu Rev Anim Biosci. 2019;7(1):89-102. https://doi.org/10.1146/annurev-animal-020518-115024.

Hayes BJ, Lewin HA, Goddard ME. The future of livestock breeding: genomic selection for efficiency, reduced emissions intensity, and adaptation. Trends Genet. 2013;29(4):206-14. https://doi.org/10.1016/j.tig.2012.11.009.

Hennig SL, McNabb BR, Trott JF, Van Eenennaam AL, Murray JD. LincRNA\#1 knockout does not affect polled phenotype in cattle. Sci Rep. 2021;8:90.

Hennig SL, Owen JR, Lin JC, McNabb BR, Van Eenennaam AL, Murray JD. Can CRISPR-mediated deletions result in a polled phenotype in Cattle? Sci Rep. 2021:3:78.

Hennig SL, Owen JR, Lin JC, Young AE, Ross PJ, Van Eenennaam AL, et al. Evaluation of mutation rates, mosaicism and off target mutations when injecting Cas9 mRNA or protein for genome editing of bovine embryos Sci Rep. 2020;10(1):22309. https://doi.org/10.1038/s41598-020-78264-8.

Heo YT, Xiaoyuan Q, Nan XY, Soonbong B, Hwan C, Nam-Hyung K, et al. CRISPR/Cas9 nuclease-mediated gene knock-in in bovine-induced pluripotent cells. Stem Cells Develop. 2015;24(3):393-402. https://doi. org/10.1089/scd.2014.0278.

Herrero M, Havlík P, Valin H, Notenbaert A, Rufino MC, Thornton PK, et al. Biomass use, production, feed efficiencies, and greenhouse gas emissions from global livestock systems. Proc Natl Acad Sci. 2013;110(52):2088893. https://doi.org/10.1073/pnas.1308149110.

Heyman Y, Chavatte-Palmer P, LeBourhis D, Camous S, Vignon X, Renard JP. Frequency and occurrence of late-gestation losses from cattle cloned embryos. Biol Reprod. 2002;66(1):6-13. https://doi.org/10.1095/biolr eprod66.1.6.

Heyman Y, Vignon X, Chesné P, Le Bourhis D, Marchal J, Renard J-P. Cloning in cattle: from embryo splitting to somatic nuclear transfer. Reprod Nutr Dev. 1998;38(6):595-603.

International Committee for Animal Recording (ICAR). ICAR Guidelines: Section 6 - Al and ET. St. Joseph, MO; 2017. https://www.icar.org/Guide lines/06-Al-and-ET.pdf. Accessed 10 Oct 2021.

International Committee for Animal Recording (ICAR). ICAR Guidelines: Section 18 - Breed Associations. St. Joseph, MO; 2019. https://www.icar.org/ Guidelines/18-Breed-Associations.pdf. Accessed 10 Oct 2021.

Ideta A, Yamashita S, Seki-Soma M, Yamaguchi R, Chiba S, Komaki H, et al. Generation of exogenous germ cells in the ovaries of sterile NANOS3-null beef cattle. Sci Rep. 2016:6:24983. https://doi.org/10.1038/srep24983.

IETS. Data Retrieval Committee Reports. International Embryo Transfer Society (IETS). 2000-2019. https://www.iets.org/Committees/Data-RetrievalCommittee.

Ikeda M, Matsuyama S, Akagi S, Ohkoshi K, Nakamura S, Minabe S, et al. Correction of a disease mutation using CRISPR/Cas9-assisted genome editing in Japanese Black Cattle. Sci Rep. 2017;7(1):17827. https://doi. org/10.1038/s41598-017-17968-w.

Ishikura Y, Yabuta Y, Ohta H, Hayashi K, Nakamura T, Okamoto I, et al. In vitro derivation and propagation of spermatogonial stem cell activity from mouse pluripotent stem cells. Cell Rep. 2016;17(10):2789-804. https:// doi.org/10.1016/j.celrep.2016.11.026.

Ishino T, Hashimoto M, Amagasa M, Saito N, Dochi O, Kirisawa R, et al. Establishment of protocol for preparation of gene-edited bovine earderived fibroblasts for somatic cell nuclear transplantation. Biomed Res. 2018;39(2):95-104. https://doi.org/10.2220/biomedres.39.95.

Jenko J, Gorjanc G, Cleveland MA, Varshney RK, Whitelaw CBA, Woolliams JA, et al. Potential of promotion of alleles by genome editing to improve 
quantitative traits in livestock breeding programs. Genet Sel Evol. 2015;47(1):55. https://doi.org/10.1186/s12711-015-0135-3.

Kadarmideen HN, Mazzoni G, Watanabe YF, Strøbech L, Baruselli PS, Meirelles $\mathrm{FV}$, et al. Genomic selection of in vitro produced and somatic cell nuclear transfer embryos for rapid genetic improvement in cattle production. Anim Reprod Sci. 2015;12(3):8.

Kambadur R, Sharma M, Smith TP, Bass JJ. Mutations in myostatin (GDF8) in double-muscled Belgian Blue and Piedmontese cattle. Genome Res. 1997:7(9):910-6. https://doi.org/10.1101/gr.7.9.910.

Karavolias NG, Horner W, Abugu MN, Evanega SN. Application of gene editing for climate change in agriculture. Front Sustain Food Syst. 2021;5:296. https://doi.org/10.3389/fsufs.2021.685801.

Karembu M. Genome Editing in Africa's Agriculture 2021: An Early Take-of. Nairobi, Kenya: International Service for the Acquisition of Agri-biotech Applications (ISAAA AfriCenter); 2021. http://africenter.isaaa.org/wpcontent/uploads/2021/04/GENOME-EDITING-IN-AFRICA-FINAL.pdf

Kasinathan P, Wei H, Xiang T, Molina JA, Metzger J, Broek D, et al. Acceleration of genetic gain in cattle by reduction of generation interval. Sci Rep. 2015;5:8674. https://doi.org/10.1038/srep08674.

Kawaguchi T, Tsukiyama T, Kimura K, Matsuyama S, Minami N, Yamada M, et al. Generation of Naïve Bovine induced pluripotent stem cells using PiggyBac transposition of doxycycline-inducible transcription factors. PLoS ONE. 2015;10(8): e0135403. https://doi.org/10.1371/journal.pone. 0135403.

Keefer CL. Artificial cloning of domestic animals. Proc Natl Acad Sci. 2015;112(29):8874-8. https://doi.org/10.1073/pnas.1501718112.

Khapayi M, Celliers PR. Factors limiting and preventing emerging farmers to progress to commercial agricultural farming in the King William's Town area of the Eastern Cape Province, South Africa. South Afr J Agric Extension. 2016:44:25-41.

Kim D, Jung Y-G, Roh S. Microarray analysis of embryo-derived bovine pluripotent cells: The vulnerable state of bovine embryonic stem cells. PLoS ONE. 2017;12(3):e0173278.

Kim J, Hanotte O, Mwai OA, Dessie T, Bashir S, Diallo B, et al. The genome landscape of indigenous African cattle. Genome Biol. 2017;18(1):34. https:// doi.org/10.1186/s13059-017-1153-y.

Kuehn LA, Keele JW, Bennett GL, McDaneld TG, Smith TPL, Snelling WM, et al. Predicting breed composition using breed frequencies of 50,000 markers from the US Meat Animal Research Center 2,000 Bull Project 1,2. J Anim Sci. 2011;89(6):1742-50. https://doi.org/10.2527/jas.2010-3530.

Laible G, Cole S-A, Brophy B, Wei J, Leath S, Jivanji S, et al. Holstein Friesian dairy cattle edited for diluted coat color as adaptation to climate change. bioRxiv. 2020. https://doi.org/10.1101/2020.09.15.298950.

Lauri A, Lazzari G, Galli C, Lagutina I, Genzini E, Braga F, et al. Assessment of MDA efficiency for genotyping using cloned embryo biopsies. Genomics. 2013;101(1):24-9. https://doi.org/10.1016/j.ygeno.2012.09.002.

Ledford H. New rules will make UK gene-edited crop research easier. Nat News. 2021. https://doi.org/10.1038/d41586-021-01572-0.

Li P, Tong C, Mehrian-Shai R, Jia L, Wu N, Yan Y, et al. Germline competent embryonic stem cells derived from rat blastocysts. Cell. 2008;135(7):1299-310. https://doi.org/10.1016/j.cell.2008.12.006

Lin JC, Van Eenennaam AL. Electroporation-mediated genome editing of livestock zygotes. Front Genet. 2021;12:546. https://doi.org/10.3389/ fgene.2021.648482.

Liu X, Wang Y, Guo W, Chang B, Liu J, Guo Z, et al. Zinc-finger nickase-mediated insertion of the lysostaphin gene into the beta-casein locus in cloned cows. Nat Commun. 2013;4(1):2565. https://doi.org/10.1038/ncomm s3565.

Liu X, Wang Y, Tian Y, Yu Y, Gao M, Hu G, et al. Generation of mastitis resistance in cows by targeting human lysozyme gene to $\beta$-casein locus using zinc-finger nucleases. Proc R Soc Biol Sci. 2014;281 (1780):20133368. https://doi.org/10.1098/rspb.2013.3368.

Loi P, Toschi P, Zacchini F, Ptak G, Scapolo PA, Capra E, et al. Synergies between assisted reproduction technologies and functional genomics. Genet Sel Evol. 2016;48(1):53. https://doi.org/10.1186/s12711-016-0231-z.

Lopes RFF, Forell F, Oliveira ATD, Rodrigues JL. Splitting and biopsy for bovine embryo sexing under field conditions. Theriogenology. 2001:56(9):1383-92. https://doi.org/10.1016/S0093-691X(01)00641-0.

Luo J, Song Z, Yu S, Cui D, Wang B, Ding F, et al. Efficient Generation of Myostatin (MSTN) biallelic mutations in cattle using zinc finger nucleases. PLoS ONE. 2014;9(4): e95225. https://doi.org/10.1371/journal.pone.0095225.
Lush JL. Animal Breeding Plans. Ames, IA: Collegiate Press, Inc.; 1937.

Mapiye C, Chikwanha OC, Chimonyo M, Dzama K. Strategies for sustainable use of indigenous cattle genetic resources in Southern Africa. Diversity. 2019;11(11):214

Mapiye O, Makombe G, Mapiye C, Dzama K. Limitations and prospects of improving beef cattle production in the smallholder sector: a case of Limpopo Province. South Africa Trop Anim Health Prod. 2018;50(7):1711-25. https://doi.org/10.1007/s11250-018-1632-5.

Mapletoft RJ, Bó GA, Baruselli PS, Menchaca A, Sartori R. Evolution of knowledge on ovarian physiology and its contribution to the widespread application of reproductive biotechnologies in South American cattle. Animal Reprod (AR). 2018;15(Supplement 1):1003-14.

Marshall K, Gibson JP, Mwai O, Mwacharo JM, Haile A, Getachew T, et al. Livestock genomics for developing countries - African examples in practice. Front Genet. 2019;10:297. https://doi.org/10.3389/fgene.2019. 00297.

McFarlane GR, Salvesen HA, Sternberg A, Lillico SG. On-farm livestock genome editing using cutting edge reproductive technologies. Front Sustain Food Syst. 2019;3:106. https://doi.org/10.3389/fsufs.2019.00106.

McLean Z, Oback B, Laible G. Embryo-mediated genome editing for accelerated genetic improvement of livestock. Front Agric Sci Eng. 2020;7(2):148-60. https://doi.org/10.15302/j-fase-2019305.

McLean ZL, Appleby SJ, Wei J, Snell RG, Oback B. Testes of DAZL null neonatal sheep lack prospermatogonia but maintain normal somatic cell morphology and marker expression. Mol Reprod Dev. 2021;88(1):3-14. https://doi.org/10.1002/mrd.23443.

McPherron AC, Lee S-J. Double muscling in cattle due to mutations in the myostatin gene. Proc Natl Acad Sci. 1997;94(23):12457-61. https://doi. org/10.1073/pnas.94.23.12457.

Meuwissen T, Hayes B, Goddard M. Accelerating improvement of livestock with genomic selection. Annu Rev Anim Biosci. 2013;1(1):221-37. https://doi.org/10.1146/annurev-animal-031412-103705.

Meuwissen THE, Hayes BJ, Goddard ME. Prediction of total genetic value using genome-wide dense marker maps. Genetics. 2001;157(4):1819-29.

Miao D, Giassetti MI, Ciccarelli M, Lopez-Biladeau B, Oatley JM. Simplified pipelines for genetic engineering of mammalian embryos by CRISPR-Cas9 electroporation. Biol Reprod. 2019;101(1):177-87. https://doi.org/10. 1093/biolre/ioz075

Misica-Turner PM, Oback FC, Eichenlaub M, Wells DN, Oback B. Aggregating embryonic but not somatic nuclear transfer embryos increases cloning efficiency in cattle1. Biol Reprod. 2007;76(2):268-78. https://doi.org/10. 1095/biolreprod.106.050922.

Meat and Livestock Australia Limited (MLA). Strategies to increase the adoption of Al in northern Australian tropical beef genotype herds. North Sydney, NSW; 2015. http://www.animalwelfarestandards.net.au/. Accessed 4 Apr 2019

Moore JK, Haber JE. Cell cycle and genetic requirements of two pathways of nonhomologous end-joining repair of double-strand breaks in Saccharomyces cerevisiae. Mol Cell Biol. 1996;16(5):2164-73. https://doi.org/ 10.1128/mcb.16.5.2164.

Mora C, Menozzi D, Kleter G, Aramyan L, Valeeva N, Zimmermann Kl, et al. Factors Affecting the Adoption of Genetically Modified Animals in the Food and Pharmaceutical Chains. Bio-based Appl Econ. 2012;1:3 doi:https://doi.org/10.13128/BAE-11706.

Mueller ML, Cole JB, Connors NK, Johnston DJ, Randhawa IAS, Van Eenennaam AL. Comparison of Gene Editing Versus Conventional Breeding to Introgress the POLLED Allele Into the Tropically Adapted Australian Beef Cattle Population. Front Genet. 2021;12:68. https://doi.org/10.3389/ fgene.2021.593154.

Mueller ML, Cole JB, Sonstegard TS, Van Eenennaam AL. Comparison of gene editing versus conventional breeding to introgress the POLLED allele into the US dairy cattle population. J Dairy Sci. 2019;102(5):4215-26. https://doi.org/10.3168/jds.2018-15892.

Mullaart E, Wells D. Embryo Biopsies for Genomic Selection. In: Niemann H, Wrenzycki C, editors. Animal Biotechnology 2: Emerging Breeding Technologies. Cham: Springer International Publishing; 2018. p. 81-94.

Mwai O, Hanotte O, Kwon YJ, Cho S. African indigenous cattle: unique genetic resources in a rapidly changing world. Asian-Australas J Anim Sci. 2015;28(7):911-21. https://doi.org/10.5713/ajas.15.0002R.

Namula Z, Wittayarat M, Hirata M, Hirano T, Nguyen NT, Le QA, et al. Genome mutation after the introduction of the gene editing by electroporation of Cas9 
protein (GEEP) system into bovine putative zygotes. In Vitro Cell Dev Biol Anim. 2019;55(8):598-603. https://doi.org/10.1007/s11626-019-00385-w.

NASEM. Science Breakthroughs to Advance Food and Agricultural Research by 2030. Washington, DC: National Academies of Sciences, Engineering, and Medicine: The National Academies Press; 2018. p. 200. https://www.nap. edu/catalog/25059/science-breakthroughs-to-advance-food-and-agricultur al-research-by-2030

Nasser LF, Reis EL, Oliveira MA, Bó GA, Baruselli PS. Comparison of four synchronization protocols for fixed-time bovine embryo transfer in Bos indicus x Bos taurus recipients. Theriogenology. 2004;62(9):1577-84. https://doi.org/10. 1016/j.theriogenology.2004.03.013.

Nyamushamba GB, Mapiye C, Tada O, Halimani TE, Muchenje V. Conservation of indigenous cattle genetic resources in Southern Africa's smallholder areas: turning threats into opportunities - a review. Asian-Australas J Anim Sci. 2017;30(5):603-21. https://doi.org/10.5713/ajas.16.0024.

O'Toole JF, Bruggeman LA, Madhavan S, Sedor JR. The cell biology of APOL1. Semin Nephrol. 2017;37(6):538-45. https://doi.org/10.1016/j.semne phrol.2017.07.007.

Oback B, Wells DN. Cloning Cattle. Cloning Stem Cells. 2003;5(4):243-56. https://doi.org/10.1089/153623003772032763.

Ojango JM, Marete A, Mujibi F, Rao E, Poole EJ, Rege J, et al. A novel use of high density SNP assays to optimize choice of different crossbred dairy cattle genotypes in smallholder systems in East Africa: American Society of Animal Science.

Ojango JM, Wasike C, Enahoro DK, Okeyo Mwai A. Dairy production systems and the adoption of genetic and breeding technologies in Tanzania, Kenya, India and Nicaragua. Animal Genetic Resources. 2016.

Owen JR, Hennig SL, McNabb BR, Mansour TA, Smith JM, Lin JC, et al. One-step generation of a targeted knock-in calf using the CRISPR-Cas9 system in bovine zygotes. BMC Genomics. 2021;22(1):118. https://doi.org/10. 1186/s12864-021-07418-3.

Park K-E, Foster Frey J, Waters J, Simpson SG, Coutu C, Plummer S, et al. OneStep Homology Mediated CRISPR-Cas editing in zygotes for generating genome edited cattle. CRISPR J. 2020;3(6):523-34. https://doi.org/10. 1089/crispr.2020.0047.

Park K-E, Kaucher AV, Powell A, Waqas MS, Sandmaier SES, Oatley MJ, et al. Generation of germline ablated male pigs by CRISPR/Cas9 editing of the NANOS2 gene. Sci Rep. 2017;7:40176. https://doi.org/10.1038/srep4 0176 .

Petersen B. Basics of genome editing technology and its application in livestock species. Reprod Domest Anim. 2017;52(S3):4-13. https://doi.org/ 10.1111/rda.13012.

Phelps CJ, Koike C, Vaught TD, Boone J, Wells KD, Chen SH, et al. Production of a1,3-Galactosyltransferase-Deficient Pigs. Science. 2003;299(5605):4114. https://doi.org/10.1126/science.1078942.

Ponsart C, Le Bourhis D, Knijn H, Fritz S, Guyader-Joly C, Otter T, et al. Reproductive technologies and genomic selection in dairy cattle. Reprod Fertil Dev. 2013;26(1):12-21. https://doi.org/10.1071/RD13328.

Poore J, Nemecek T. Reducing food's environmental impacts through producers and consumers. Science. 2018;360(6392):987-92. https://doi.org/10. 1126/science.aaq0216.

Proudfoot C, Carlson DF, Huddart R, Long CR, Pryor JH, King TJ, et al. Genome edited sheep and cattle. Transgenic Res. 2015;24(1):147-53. https://doi. org/10.1007/s11248-014-9832-X.

Pryce JE, Haile-Mariam M. Symposium review: Genomic selection for reducing environmental impact and adapting to climate change. J Dairy Sci. 2020;103(6):5366-75. https://doi.org/10.3168/jds.2019-17732.

Pursley JR, Mee MO, Wiltbank MC. Synchronization of ovulation in dairy cows using PGF2alpha and GnRH. Theriogenology. 1995;44(7):915-23. https://doi.org/10.1016/0093-691x(95)00279-h.

Quinton CD, Hely FS, Amer PR, Byrne TJ, Cromie AR. Prediction of effects of beef selection indexes on greenhouse gas emissions. Animal. 2018;12(5):889-97. https://doi.org/10.1017/s1751731117002373.

RAAA. Beef breed approves gene-edited traits for animal registration. BEEF Magazine. 2021

Red Angus Association of America (RAAA). Rules \& Regulations, F-3. Commerce City, CO; 2021. https://redangus.org/wp-content/uploads/2021/ 06/Rules-and-Regulations-6-1-21 current.pdf. Accessed 10 Oct 2021.

Ramos-Ibeas P, Calle A, Pericuesta E, Laguna-Barraza R, Moros-Mora R, LoperaVásquez $\mathrm{R}$, et al. An efficient system to establish biopsy-derived trophoblastic cell lines from bovine embryos. Biol Reprod. 2014;91(1):15.
Rexroad C, Vallet J, Matukumalli LK, Reecy J, Bickhart D, Blackburn H, et al. Genome to Phenome: Improving Animal Health, Production, and Well-Being - A New USDA Blueprint for Animal Genome Research 2018-2027. Front Genetics. 2019;10:327. https://doi.org/10.3389/fgene. 2019.00327.

Richardson TE, Chapman KM, Dann CT, Hammer RE, Hamra FK. Sterile testis complementation with spermatogonial lines restores fertility to DAZLdeficient rats and maximizes donor germline transmission. PLOS ONE. 2009:4(7): e6308. https://doi.org/10.1371/journal.pone.0006308.

Rodriguez-Villamil P, Ongaratto FL, Bostrom JR, Larson S, Sonstegard T. Generation of SLICK beef cattle by embryo microinjection: a case report. Reprod Fertil Dev. 2021;33(2):114. https://doi.org/10.1071/RDv33 n2Ab13.

Saito S, Strelchenko N, Niemann H. Bovine embryonic stem cell-like cell lines cultured over several passages. Rouxs Arch Dev Biol. 1992;201 (3):13441. https://doi.org/10.1007/bf00188711.

Salmon GR, Marshall K, Tebug SF, Missohou A, Robinson TP, MacLeod M. The greenhouse gas abatement potential of productivity improving measures applied to cattle systems in a developing region. Animal. 2018:12(4):844-52. https://doi.org/10.1017/S1751731117002294.

Sander JD, Joung JK. CRISPR-Cas systems for editing, regulating and targeting genomes. Nat Biotechnol. 2014;32:347. https://doi.org/10.1038/nbt. 2842

Scholtz M, Bester J, Mamabolo J, Ramsay K. Results of the national cattle survey undertaken in South Africa, with emphasis on beef. Appl Anim Husb Rural Dev. 2008;1:1-9.

Segelke D, Reinhardt F, Liu Z, Thaller G. Prediction of expected genetic variation within groups of offspring for innovative mating schemes. Genet Sel Evol. 2014;46(1):42. https://doi.org/10.1186/1297-9686-46-42.

Setiana L, Saleh DM, Nugroho AP, Lana DL. Factors in the Adoption of Beef Cattle Artificial Insemination (AI) Technology in Brebes Regency. Jurnal Penyuluhan. 2020;16(1):16-23. https://doi.org/10.25015/16202027574.

Setiawan D. Artificial Insemination of Beef Cattle UPSUS SIWAB Program based on the calculation of non-return rate, service per conception and calving rate in the North Kayong Regency. Int J Trop Vet Biomed Res. 2018;3(1):7-11.

Shanthalingam S, Tibary A, Beever JE, Kasinathan P, Brown WC, Srikumaran S. Precise gene editing paves the way for derivation of Mannheimia haemolytica leukotoxin-resistant cattle. Proc Natl Acad Sci. 2016;113(46):13186-90. https://doi.org/10.1073/pnas.1613428113.

Shojaei Saadi HA, Vigneault C, Sargolzaei M, Gagné D, Fournier É, de Montera $B$, et al. Impact of whole-genome amplification on the reliability of pre-transfer cattle embryo breeding value estimates. BMC Genomics. 2014;15(1):889. https://doi.org/10.1186/1471-2164-15-889.

Sonoda E, Hochegger H, Saberi A, Taniguchi Y, Takeda S. Differential usage of non-homologous end-joining and homologous recombination in double strand break repair. DNA Repair. 2006;5(9):1021-9. https://doi. org/10.1016/j.dnarep.2006.05.022.

Soto DA, Ross PJ. Pluripotent stem cells and livestock genetic engineering. Transgenic Res. 2016;25(3):289-306.

Su X, Wang S, Su G, Zheng Z, Zhang J, Ma Y, et al. Production of microhomologous-mediated site-specific integrated LacS gene cow using TALENs. Theriogenology. 2018;1 19:282-8. https://doi.org/10.1016/j.theriogeno logy.2018.07.011.

Tait-Burkard C, Doeschl-Wilson A, McGrew MJ, Archibald AL, Sang HM, Houston RD, et al. Livestock 2.0 - genome editing for fitter, healthier, and more productive farmed animals. Genome Biol. 2018;19(1):204. https:// doi.org/10.1186/s13059-018-1583-1.

Tan W, Carlson DF, Lancto CA, Garbe JR, Webster DA, Hackett PB, et al. Efficient nonmeiotic allele introgression in livestock using custom endonucleases. Proc Natl Acad Sci. 2013;110(41):16526-31. https://doi.org/10. 1073/pnas.1310478110

Tan W, Carlson DF, Walton MW, Fahrenkrug SC, Hackett PB. Precision Editing of Large Animal Genomes. In: Friedmann T, Dunlap J, Goodwin S, editors. Advances in genetics. Waltham: Academic Press; 2012. p. 37-97.

Tan W, Proudfoot C, Lillico SG, Whitelaw CBA. Gene targeting, genome editing: from Dolly to editors. Transgenic Res. 2016;25(3):273-87. https://doi. org/10.1007/s11248-016-9932-x.

Taylor L, Carlson DF, Nandi S, Sherman A, Fahrenkrug SC, McGrew MJ. Efficient TALEN-mediated gene targeting of chicken primordial germ cells. Development. 2017;144(5):928-34. https://doi.org/10.1242/dev.145367. 
Thallman RM, Snider A. Use of Advanced Reproductive Technologies and Inclusion of these Records in Genetic Evaluation. BIF Research Symposium \& Convention; Des Moines, IA: Beef Improvement Federation (BIF).

Thompson NM, Widmar NO, Schutz MM, Cole JB, Wolf CA. Economic considerations of breeding for polled dairy cows versus dehorning in the United States. J Dairy Sci. 2017;100(6):4941-52. https://doi.org/10.3168/ jds.2016-12099.

Tominaga K, Hamada Y. Efficient production of sex-identified and cryosurvived bovine in-vitro produced blastocysts. Theriogenology. 2004;61(6):118191. https://doi.org/10.1016/j.theriogenology.2003.07.008.

Torres A, Batista M, Diniz P, Silva E, Mateus L, Lopes-da-Costa L. Effects of oocyte donor age and embryonic stage of development on transcription of genes coding for enzymes of the prostaglandins and progesterone synthesis pathways in bovine in vitro produced embryos. Zygote. 2014;23(6):802-12. https://doi.org/10.1017/S0967199414000446.

Twomey AJ, Cromie AR, McHugh N, Berry DP. Validation of a beef cattle maternal breeding objective based on a cross-sectional analysis of a large national cattle database. J Anim Sci. 2020;98:11. https://doi.org/ 10.1093/jas/skaa322.

U.S. Department of Agriculture (USDA)-Animals and Plant Health Inspection Service (APHIS)-National Animal Health Monitoring System (NAHMS). Beef Cow-calf Management Practices in the United States, 2017, report 1, \#.782.0520. Fort Collins, CO; 2020. https://www.aphis.usda.gov/ animal_health/nahms/beefcowcalf/downloads/beef2017/Beef2017_ dr_Partl.pdf. Accessed 10 Mar 2021.

van der Berg JP, Kleter GA, Battaglia E, Groenen M, Kok EJ. Developments in genetic modification of cattle and implications for regulation, safety and traceability. Front Agric Sci Eng. 2020;7(2):136-47. https://doi.org/ 10.15302/j-fase-2019306.

van der Berg JP, Kleter GA, Kok EJ. Regulation and safety considerations of somatic cell nuclear transfer-cloned farm animals and their offspring used for food production. Theriogenology. 2019;135:85-93. https://doi. org/10.1016/j.theriogenology.2019.06.001.

van Echten-Arends J, Mastenbroek S, Sikkema-Raddatz B, Korevaar JC, Heineman $\mathrm{MJ}$, van der Veen $\mathrm{F}$, et al. Chromosomal mosaicism in human preimplantation embryos: a systematic review. Hum Reprod Update. 2011;17(5):620-7. https://doi.org/10.1093/humupd/dmr014.

Van Eenennaam AL. Genetic modification of food animals. Curr Opin Biotechnol. 2017:44:27-34. https://doi.org/10.1016/j.copbio.2016.10.007.

Van Eenennaam AL. Recent Developments in Genetic Evaluations and Genomic Testing. eXtention.org; 2019. https://beef-cattle.extension.org/recent-deve opments-in-genetic-evaluations-and-genomic-testing/. Accessed 4 Oct 2021.

Van Eenennaam AL, Silva FDF, Trott JF, Zilberman D. Genetic engineering of livestock: the opportunity cost of regulatory delay. Annu Rev Anim Biosci. 2021;9(1):453-78. https://doi.org/10.1146/annurev-animal-061220-023052.

Van Eenennaam AL, Weigel KA, Young AE, Cleveland MA, Dekkers JCM. Applied animal genomics: results from the field. Annu Rev Anim Biosci. 2014;2(1):10539. https://doi.org/10.1146/annurev-animal-022513-114119.

Van Eenennaam AL, Wells KD, Murray JD. Proposed US regulation of gene-edited food animals is not fit for purpose. Sci Food. 2019;3(1):3. https://doi.org/10. 1038/s41538-019-0035-y.

Van Eenennaam AL, Werth SJ. Animal board invited review: animal agriculture and alternative meats - learning from past science communication failures. Animal. 2021;15(10): 100360. https://doi.org/10.1016/j.animal. 2021.100360

Van Eenennaam AL, Young AE. Public Perception of Animal Biotechnology. In: Niemann H, Wrenzycki C, editors. Animal Biotechnology 2: Emerging Breeding Technologies. Cham: Springer International Publishing; 2018. p. 275-303.

van Marle-Köster E, Visser C. Genetic Improvement in South African Livestock: can genomics bridge the gap between the developed and developing sectors? Front Genet. 2018;9:331. https://doi.org/10.3389/fgene.2018. 00331.

van Mil A, Hopkins H, Kinsella S. Potential uses for genetic technologies: dialogue and engagement research conducted on behalf of the Royal Society. London, England: Hopkins Van Mil: Creating Connections Ltd; 2017. https://royalsociety.org/ /media/policy/projects/gene-tech/ genetic-technologies-public-dialogue-hvm-full-report.pdf.
VanRaden PM. Improving Animals Each Generation by Selecting from the Best Gene Sources. 2007. https://aipl.arsusda.gov/publish/other/2007/Duke07_ pvr.pdf. Accessed 5 Jan 2018.

Visscher P, Haley C, Thompson R. Marker-assisted introgression in backcross breeding programs. Genetics. 1996;144(4):1923-32.

Visscher P, Pong-Wong R, Whittemore C, Haley C. Impact of biotechnology on (cross)breeding programmes in pigs. Livest Prod Sci. 2000;65(1):57-70. https://doi.org/10.1016/S0301-6226(99)00180-3.

Wei J, Wagner S, Lu D, Maclean P, Carlson DF, Fahrenkrug SC, et al. Efficient introgression of allelic variants by embryo-mediated editing of the bovine genome. Sci Rep. 2015;5(1):11735. https://doi.org/10.1038/srep11735.

Wei J, Wagner S, Maclean P, Brophy B, Cole S, Smolenski G, et al. Cattle with a precise, zygote-mediated deletion safely eliminate the major milk allergen beta-lactoglobulin. Sci Rep. 2018;8(1):7661. https://doi.org/10.1038/ s41598-018-25654-8.

Whelan Al, Lema MA. Regulatory framework for gene editing and other new breeding techniques (NBTs) in Argentina. GM Crops Food. 2015;6(4):253-65. https://doi.org/10.1080/21645698.2015.1114698.

Wiggans GR, Cole JB, Hubbard SM, Sonstegard TS. Genomic selection in dairy cattle: the USDA experience. Annu Rev Anim Biosci. 2017;5(1):309-27. https://doi. org/10.1146/annurev-animal-021815-111422.

Wilmut I, Schnieke AE, McWhir J, Kind AJ, Campbell KHS. Viable offspring derived from fetal and adult mammalian cells. Nature. 1997;385(6619):810-3. https:// doi.org/10.1038/385810a0

Wu H, Wang Y, Zhang Y, Yang M, Lv J, Liu J, et al. TALE nickase-mediated SP110 knockin endows cattle with increased resistance to tuberculosis. Proc Natl Acad Sci. 2015;112(13):E1530-9. https://doi.org/10.1073/pnas. 1421587112.

Wu J, Belmonte JCI. Dynamic pluripotent stem cell states and their applications. Cell Stem Cell. 2015;17(5):509-25. https://doi.org/10.1016/j.stem. 2015.10.009.

Ying Q-L, Wray J, Nichols J, Batlle-Morera L, Doble B, Woodgett J, et al. The ground state of embryonic stem cell self-renewal. Nature. 2008:453(7194):519. https://doi.org/10.1038/nature06968.

Yoshino T, Suzuki T, Nagamatsu G, Yabukami H, Ikegaya M, Kishima M, et al. Generation of ovarian follicles from mouse pluripotent stem cells. Science. 2021;373(6552):eabe0237. https://doi.org/10.1126/science. abe0237.

Yu S, Luo J, Song Z, Ding F, Dai Y, Li N. Highly efficient modification of betalactoglobulin (BLG) gene via zinc-finger nucleases in cattle. Cell Res. 2011;21(11):1638-40. https://doi.org/10.1038/cr.2011.153.

Yudin NS, Lukyanov KI, Voevoda MI, Kolchanov NA. Application of reproductive technologies to improve dairy cattle genomic selection. Russ J Genet Appl Res. 2016;6(3):321-9. https://doi.org/10.1134/s207905971603014x.

Zhao L, Gao X, Zheng Y, Wang Z, Zhao G, Ren J, et al. Establishment of bovine expanded potential stem cells. Proc Natl Acad Sci. 2021;118(15): e2018505118. https://doi.org/10.1073/pnas.2018505118.

\section{Publisher's Note}

Springer Nature remains neutral with regard to jurisdictional claims in published maps and institutional affiliations.

Ready to submit your research? Choose BMC and benefit from:

- fast, convenient online submission

- thorough peer review by experienced researchers in your field

- rapid publication on acceptance

- support for research data, including large and complex data types

- gold Open Access which fosters wider collaboration and increased citations

- maximum visibility for your research: over 100M website views per year

At BMC, research is always in progress.

Learn more biomedcentral.com/submissions 